\title{
Flow Uniformity Calibration of AMELIA's Circulation Control Wings
}

\author{
Eric N. Paciano ${ }^{*}$ and Jonathan A. Lichtwardt ${ }^{\dagger}$, and David D. Marshall ${ }^{*}$ \\ California Polytechnic State University, San Luis Obispo, CA, 93407-0352 \\ Kristina K. Jameson ${ }^{\S}$ \\ Space Systems/Loral, Palo Alto, CA, 94303 \\ Robert K. Fong ${ }^{* *}$ \\ Experimental Aerophysics Branch, NASA Ames Research Center, Moffett Field, CA, 94035.
}

This paper details the extensive effort required to achieve uniform flow from the AMELIA wind tunnel model's circulation control wings. Performed in September of 2011 in the Fluid Mechanics Lab at NASA Ames Research Center, the calibration required a 500hp instrument-quality air compressor capable of delivering $250 \mathrm{CFM}$ at pressures greater than 70 psi. It was found that the geometery within AMELIA's circulation control supply plenums produced highly vortical flow, resulting in poor circulation control performance as measured by traversing external and stationary internal total pressure probes, as well as surface oil flow. Adjustments were made within AMELIA to the supply conditions of each plenum including internal butterfly valve position, model inlet pressure, and total volume flow rate delivered to the model. Each plenum was further modified with a treatment of metal foam and various other materials including perforated plates, metal barriers, and Rigimesh material. The combination of metal foam and densly woven Rigimesh resulted in uniform spanwise flow at acceptable plenum pressures.

\section{Nomenclature}

$c \quad=$ wing chord, inches

$h \quad=$ height, inches

$r \quad=$ radius, inches

Subscripts

Slot $=$ circulation control jet nozzle

Acronyms

AMELIA = advanced model for extreme lift and improved aeroacoustics

$F M L=$ fluid mechanics lab

$L E \quad \quad=$ leading edge

$L E I B=$ leading edge inboard

$\angle E O B=$ leading edge outboard

$N R A=$ NASA research announcement

$T E=$ trailing edge

$T E I B=$ trailing edge inboard

$T E O B=$ trailing edge outboard

\footnotetext{
* Graduate Student, Aerospace Engineering Department, Student Member AIAA.

${ }^{\dagger}$ Graduate Student, Aerospace Engineering Department, Student Member AIAA.

* Associate Professor, Aerospace Engineering Department, Senior Member AIAA.

${ }^{\S}$ Propulsion Specialist, Member AIAA.

** Project Manager, Experimental Aerophysics Branch, NASA Ames Research Center, Mail Stop N260, Moffett Field CA 94035
} 


\section{Introduction}

$\mathrm{T}$ HE flow uniformity calibration of the circulation control system (on the Advanced Model for Extreme Lift and Improved Aeroacoustics or AMELIA), was conducted in preparation for the December 2011 wind tunnel test. The efforts outlined herein were part of a larger body of work to fulfill a NASA Research Announcement(NRA) awarded to Dr. David Marshall of the California Polytechnic State University, San Luis Obispo Aerospace Engineering Department. The NRA involved the design and wind tunnel testing of a regional CESTOL airliner, with the intention of providing a comprehensive dataset for CFD validation. The calibration discussed in the following was conducted in the final year of the research grant, on the ten foot span AMELIA wind tunnel model. For the sake of all parties, the author assumes the reader is familiar with the model's design and project's goals - an overview of the model is presented in the appendix of this report. For more information on the aircraft design, wind tunnel model, wind tunnel test, results, and project as a whole see ref. 1-4.

\section{Circulation Control Slot Design Considerations}

Circulation control plenums have evolved drastically from the cumbersome, bolt on additions used in static tests on the QSRA ${ }^{5}$ in the 80 's, to the advanced plenum designs with internal slot height sensors used recently by Jones ${ }^{6}$. Many past circulation control wind tunnel experiments have been conducted using an elliptical airfoil with a circular trailing edge $\mathrm{e}^{7-11}$. Over the years this geometry and slight variations of it have provided a thorough foundation of circulation control data. An example of an elliptical airfoil configuration can be seen in Figure 1 and Figure 2. While this configuration continues to be relevant in many areas of research, recently circulation control airfoils have changed shape to reflect the state of the art in next generation commercial transport wing design.

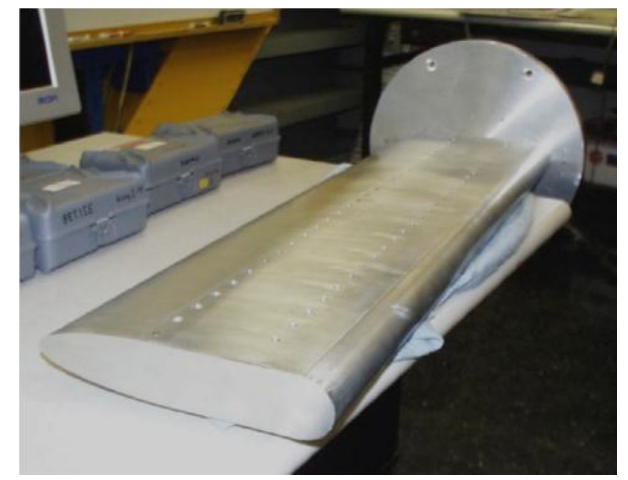

Figure 1. Elliptical circulation control airfoil model with rounded trailing edge ${ }^{7}$.

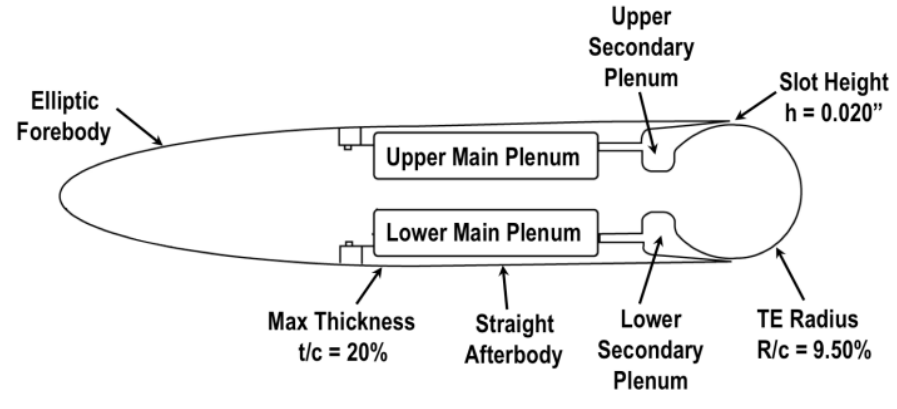

Figure 2. Cross section of the elliptical airfoil ${ }^{6}$.

Recently manufactured circulation control wind tunnel test articles depart from the circular trailing edge in favor of a dual radius flap design. In principal the dual radius flap enables the preservation of plenum geometry despite an adjustable flap deflection. The cross section of a circulation control wing using a dual radius plain flap can be seen in Figure $3^{12}$. AMELIA employs a simplified version of the dual radius flap shown in the figure, wherein flap deflection is fixed for a given set of flaps.

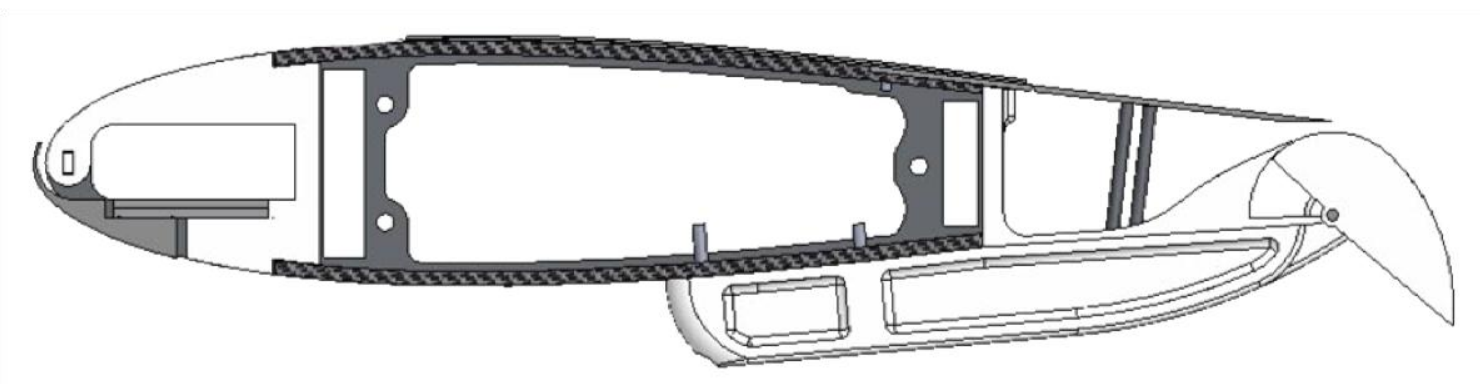

Figure 3. Cross section of a circulation control wing using a dual radius flap ${ }^{12}$. 
One of the major considerations influencing the design of the circulation control plenum was the plenum/flap attachment. With slot height as small as 0.012 " in some places, a continuous jet expansion surface was desired that would allow the boundary layer to grow from the plenum inlet, throughout the slot, and onto the flap surface. In order to achieve a continuous surface, each flap would need to extend into the plenum where it would attach near the start of the nozzle converging section. This design, although ideal with respect to the circulation control flow quality, proved problematic in that the slot height (a critical value in the determination of the discharge coefficient and flap performance) would need to be remeasured after each flap change. Alternatively, the flap could be manufactured to attach outside of the circulation control plenum, however the transition from flap to plenum would remain the primary concern.

Other significant design considerations included the resistance of the plenum structure in expansion under the force of pressurization and local temperature gradients. Accurate knowledge of the slot height throughout the wind tunnel test was a top priority, as an expansion of only a few thousandths of an inch could be a large increase relative to the small nominal height. Two methods were considered to maintain the true slot height. The first used a pair of set-screws and tie-downs placed at close intervals along the length of the plenum in the spanwise direction. This method would allow the restricting structural device to be placed within the plenum at a distance (from the exit) sufficient to not disturb the slot flow. It would also allow for local adjustability of the slot height, permitting precision control on-the-fly (when the system is under pressure). The set-screw/tie-down method had prior success in wind tunnel tests executed by Englar and Cattafesta ${ }^{12,13}$. The second method involved placing rigid supports within the plenum at intervals along the span of the slot. These thin supports would reside within the slot itself, and would be secured to both the lower (nozzle) surface and the upper skin ${ }^{6}$. Later versions of this method included supports only in the nozzle section of the plenum - terminating before they reach the slot (similar to the "standoffs" in Figure 4). The primary concern with this method of support is its close proximity to the slot itself, and the resulting influence on the slot flow.

The flow straightening treatment within each plenum was also a consideration when formulating the design of the circulation control plenums. With the required instrumentation and structure within AMELIA's wings, only a limited amount of volume could be allocated to the plenums. Similar circumstances had been seen in previous wind tunnel tests, where the plenum volume was insufficient to establish a truely stagnant condition. In these previous tests choke plates were employed to act as a flow restriction device and unify the conditions along the length of the plenum. The design of the air supply system leading to the circulation control plenums within AMELIA only intensified the need for flow treatment - as each narrow plenum was fed by only a single source at one end. Figure 4 and Figure 5 show the internals of the FAST-MAC model with multiple plenum supply locations and choke plate in contrast to the AMELIA model configuration with a single plenum supply ${ }^{6}$. The type of plenum treatment to use on the AMELIA model was the subject of lengthy debate. Choke plates seemed to offer the most promise, and were successfully applied in similar cases, however acousticians worried the small orifices in the plates would emit high frequency noise that could be indistinguishable from the slot noise. This was highly undesirable as acoustic characterization of the slot flow was a major priority of the wind tunnel test. Other options for flow treatment included a metal foam product manufactured by ERG Aerospace. The foam could be manufactured to appropriate

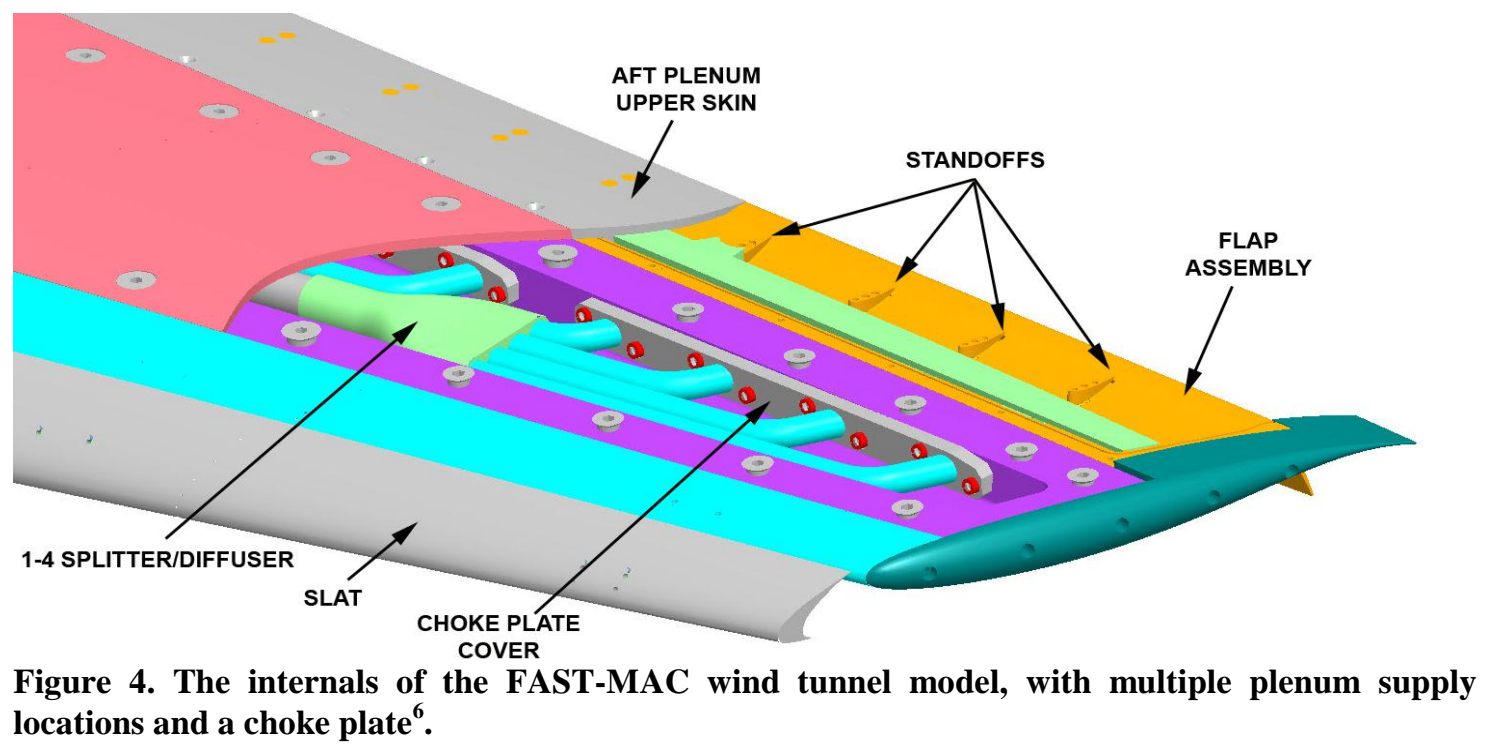




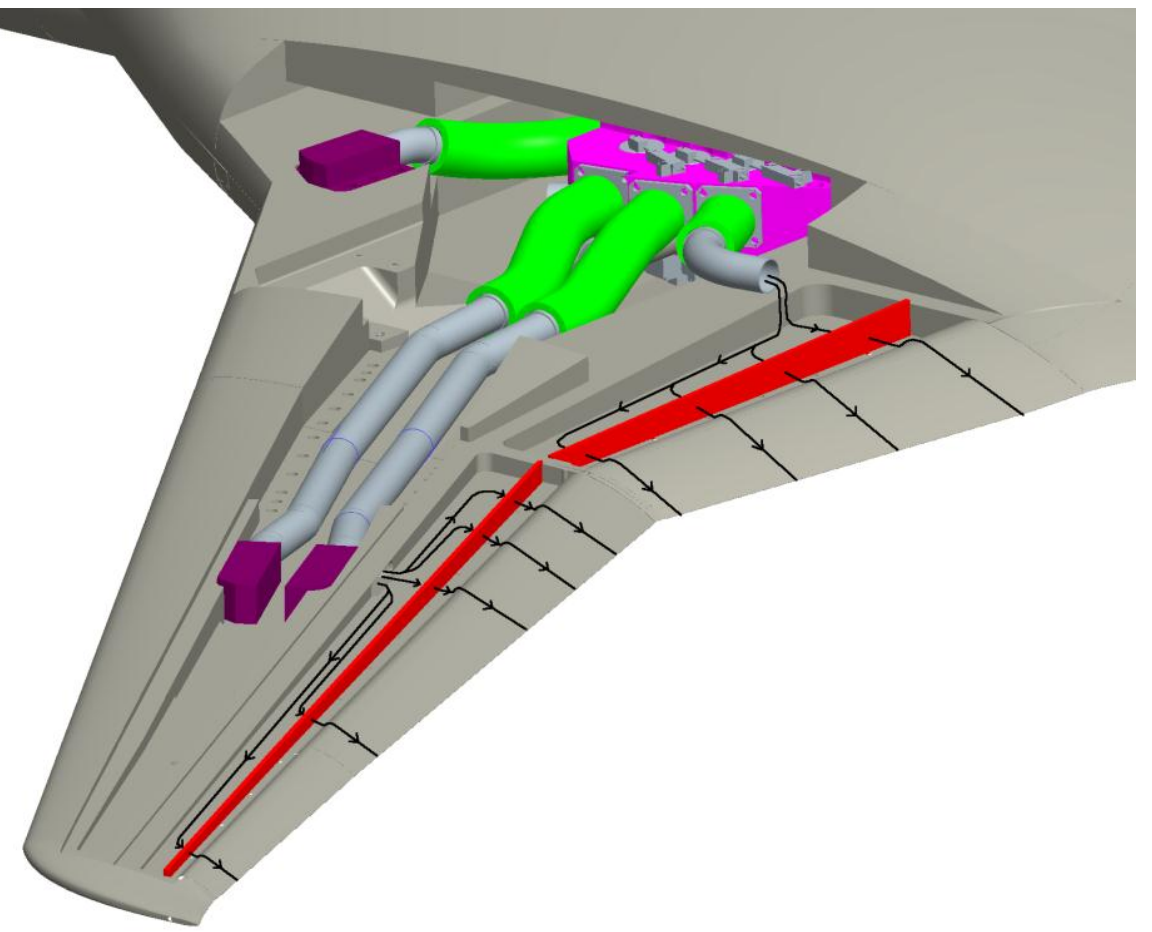

Figure 5. Circulation control supply system inside the AMELIA model, each plenum supplied by a single source.

tolerances, and was available in many porosities, the manufacturer also provided data showing its ability to provide a pressure reduction in fluid flow.

Minimizing breaks in the slot caused by plenum intersections was a high priority in terms of providing clean circulation control flow across the upper surface of the wing and flaps. In order to achieve this, many plenum layout designs were considered, including a design that allowed air to pass freely from inboard to outboard plenum. Other designs (like the one shown in Figure 5) included separate inboard and outboard plenums, allowing for independent pressure control. The separating structure, at both the leading and trailing edge in this design, tapered as it approached the slot face in order to minimize unblown regions. Although the unblown region at the wing break was minimized, it could not be completely eliminated.

The majority of the plenum design characteristics (nozzle contraction ratio, plenum aspect ratio, slot height to chord ratio) were based on values used in previous models and suggestions from Englar and Jones. 


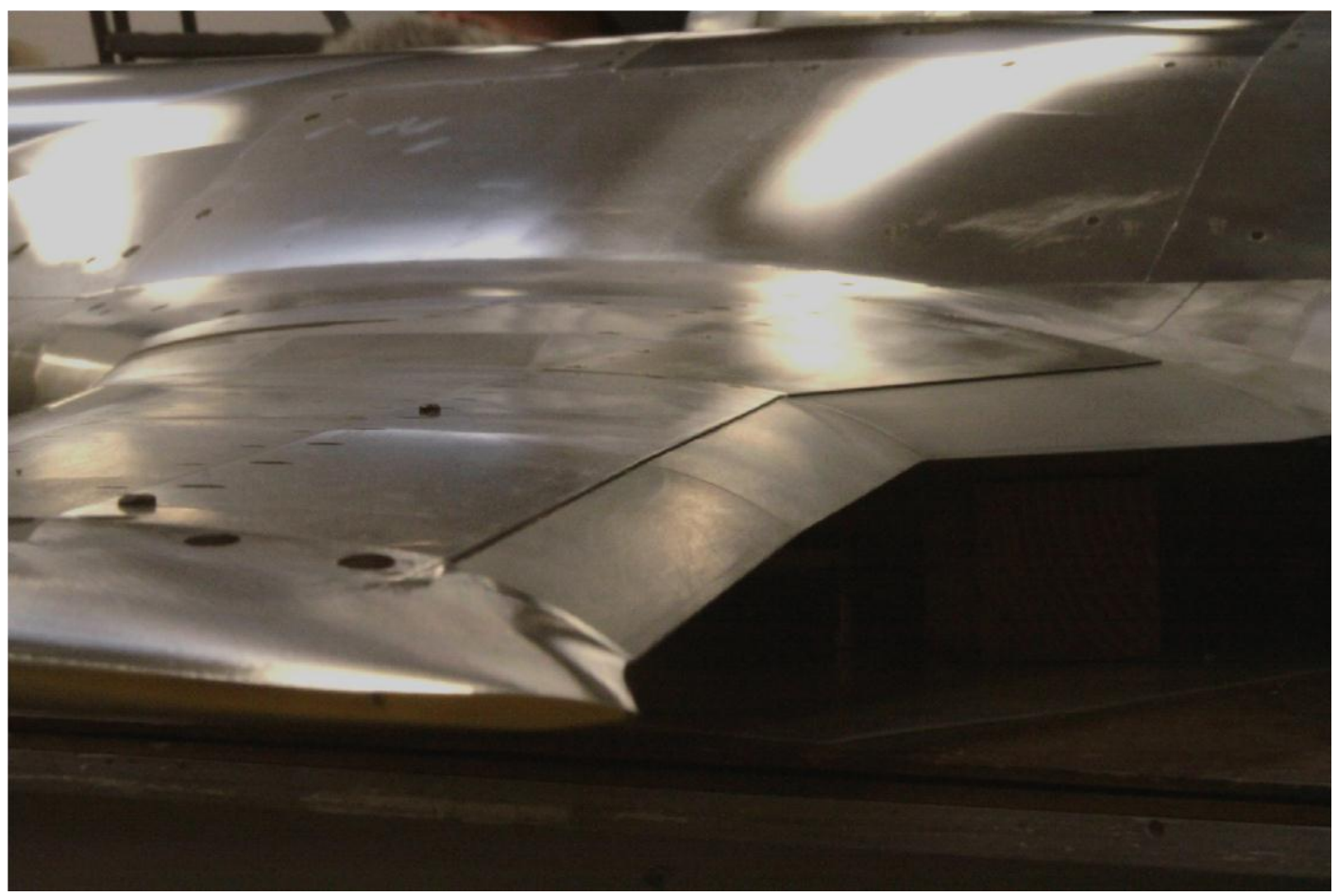

Figure 6. The trailing edge slot on an (unpainted) AMELIA.

\section{Slot Calibration}

AMELIA's slot configuration can be viewed in Figure 6 for the trailing edge of the left wing. The model is shown with a zero degree flap, and no surface treatment (this image was captured during model construction at PatersonLabs). The flap joins to the model just aft of the circulation control slot, which allows for the preservation of the slot height despite flap changes. Adjustments to the slot height are enabled through the set-screw/tie down method discussed in the previous section and seen in Figure 7.

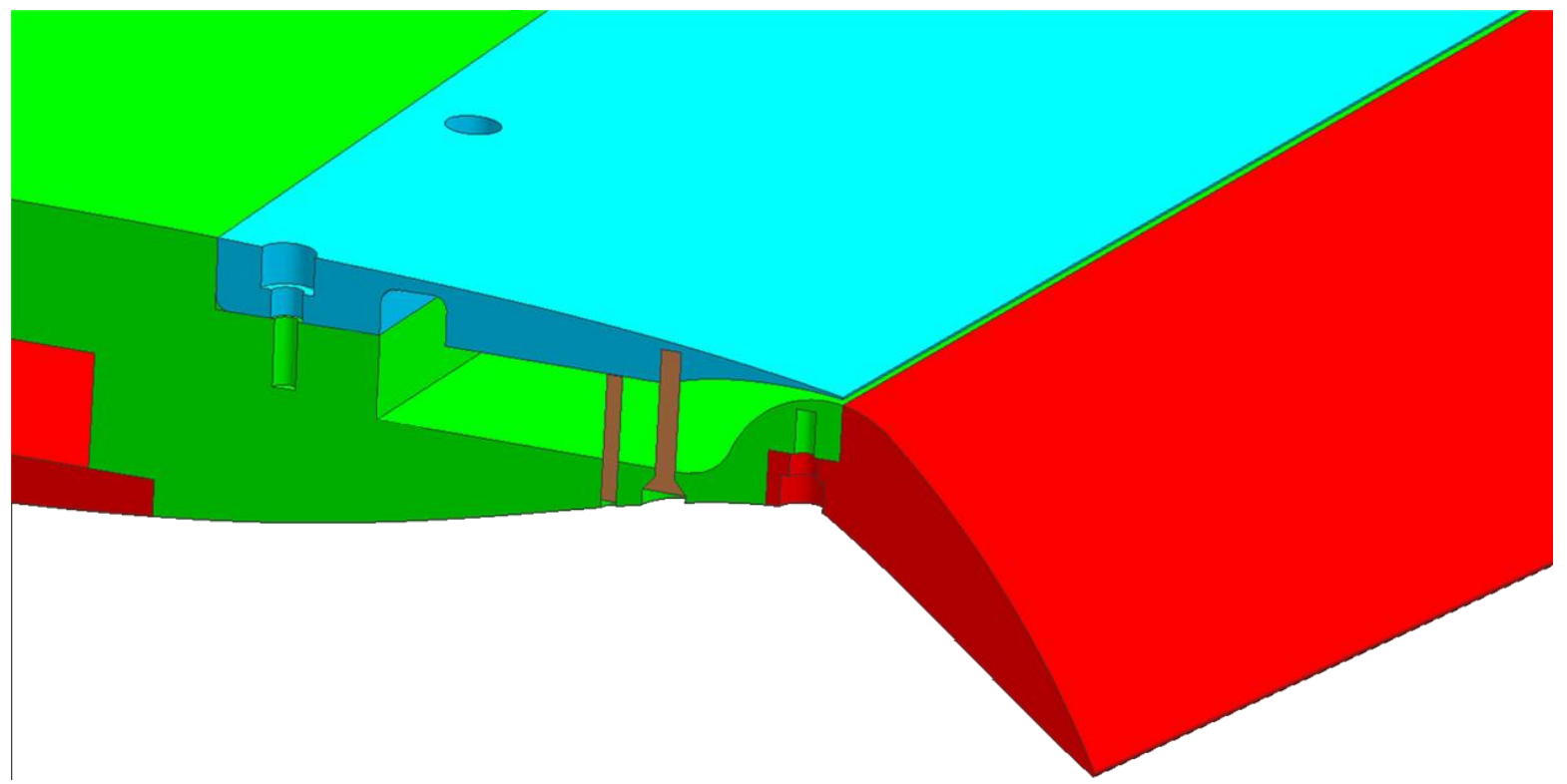

Figure 7. Cut-view of AMELIA's wing showing trailing edge plenum shape and flap attachment. 
The final plenum layout can be seen in Figure 8. Each of AMELIA's wings uses four plenums (two leading edge and two trailing edge). The trailing edge plenum covers are incorporated into the skin of the upper surface, while the leading edge covers make up the lower surface. Each inboard plenum terminates at the wing break (approx. 29.5" from model centerline), the outboard plenums terminate at the wingtip (roughly 58.5 " from the model centerline). A detailed view of the plenum is shown in Figure 9, data associated with the figure is presented in Table 1.

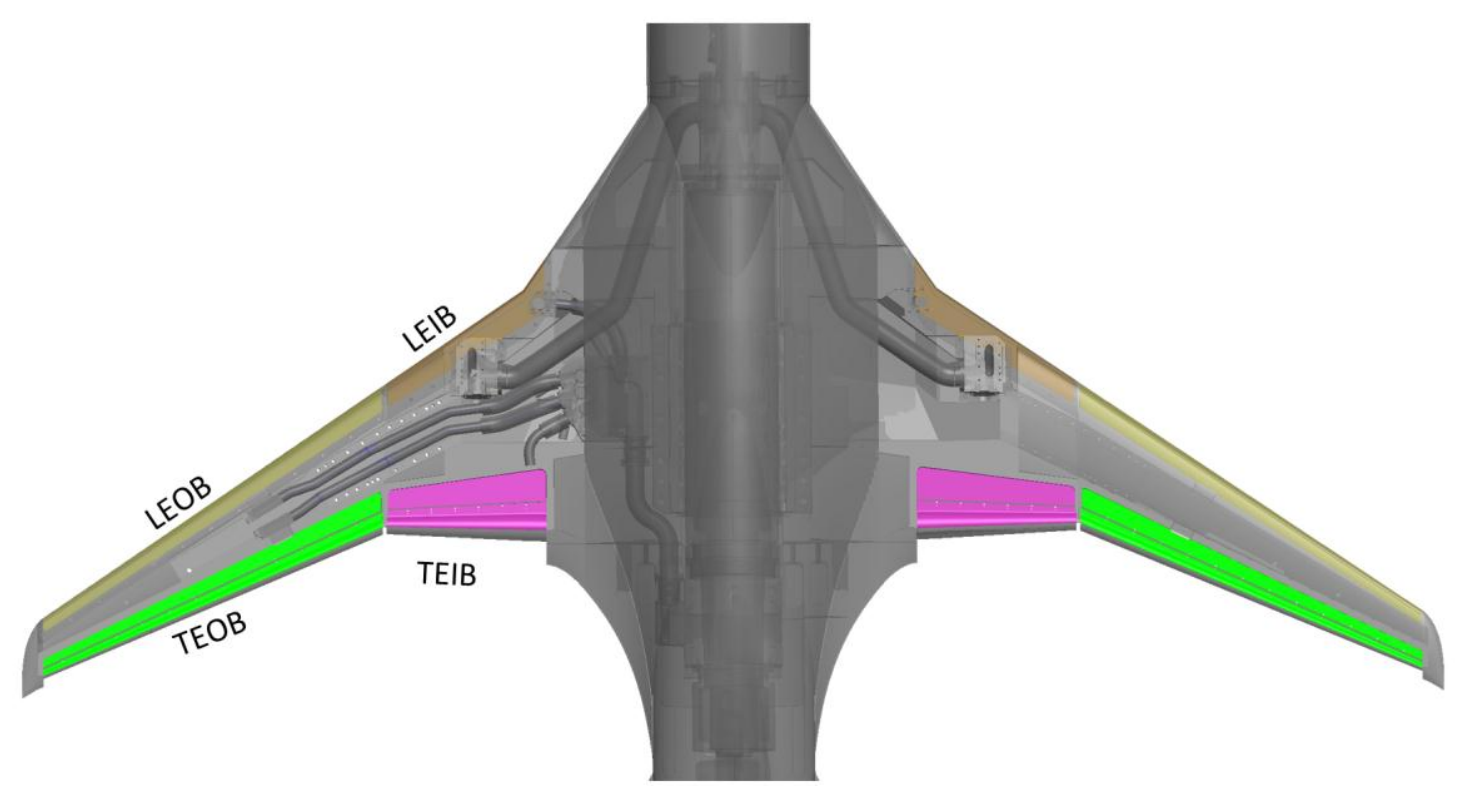

Figure 8. Circulation control plenum layout.

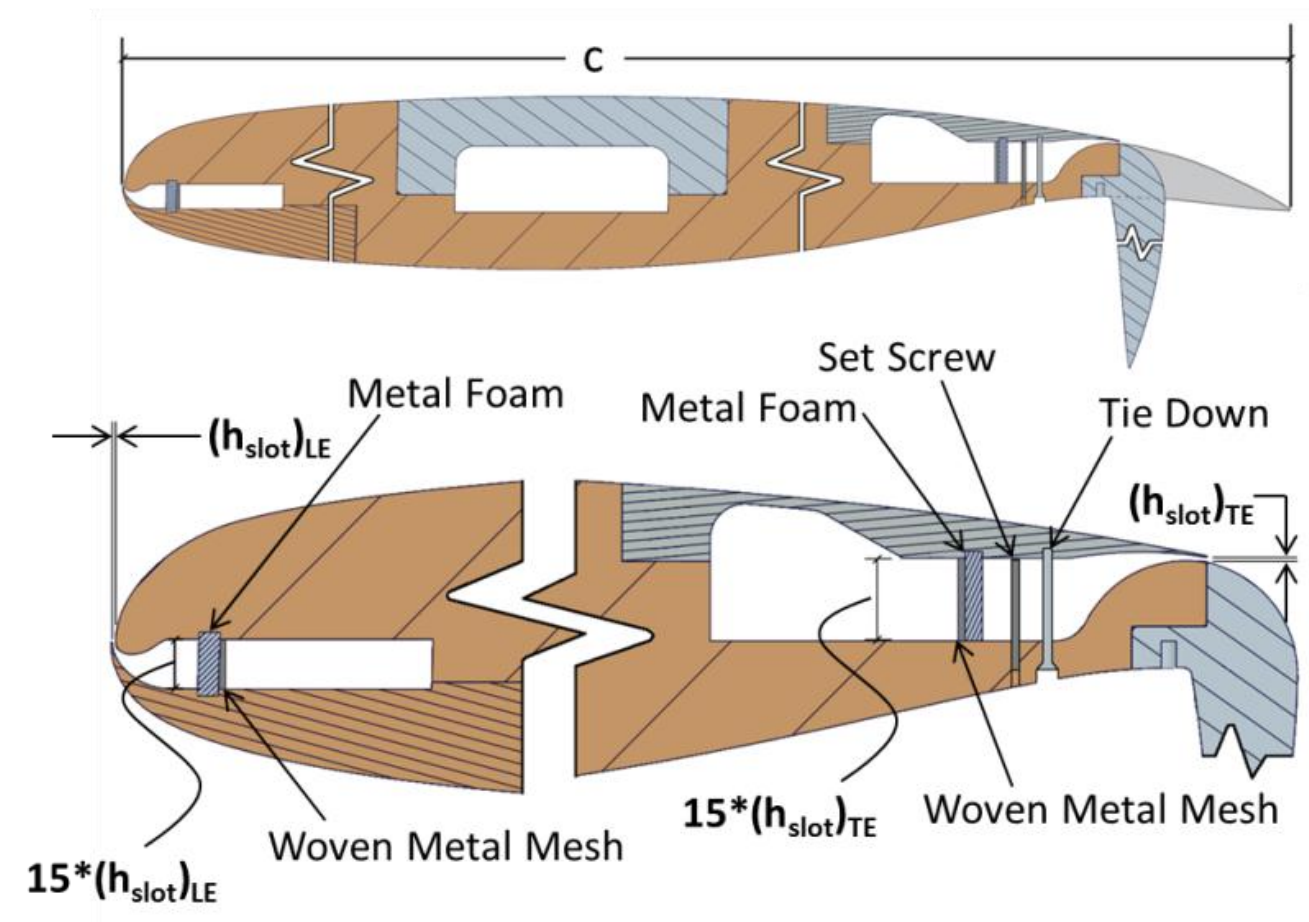

Figure 9. Detailed view of the circulation control plenums. 
Table 1. Leading and trailing edge plenum design details.

\begin{tabular}{|c|c|c|}
\hline & Leading Edge & Trailing Edge \\
\hline $\mathbf{h}_{\text {slot }} / \mathbf{c}$ & $0.001428 *$ & 0.00238 \\
\hline Contraction Ratio & $15: 1$ & $15: 1$ \\
\hline Minimum Lip Thickness & $0.01^{\prime \prime}$ & $0.01^{\prime \prime}$ \\
\hline
\end{tabular}

The information presented in the above table and figure define the design parameters used in the manufacturing of AMELIA ("Lip" here is defined as the material at the upper surface of the jet nozzle). The slot height was adjusted to the ideal values (shown above) through use of the set-screw/tie down pairs (for more information on the actual slot height compared to the ideal see the slot height section). In order to condition the circulation control flow, each plenum contains a barrier of a woven metal mesh and metal foam.

\section{A. Metal Foam}

Slot flow conditioning was achieved using a metal foam product manufactured by ERG Aerospace. During the slot flow calibration effort, metal foam with $12-15 \%$ density and 6-8\% density were tested (both sets of foam contained approximately 40 pores per inch). The foam density value is a ratio of the mass of the foam divided by its original mass of aluminum (prior to undergoing the chemical process that creates the cavities). The higher density foam was found to be more effective in resisting flow (thus providing more straightening), and its rigidity made it more easily manipulated. Although each piece of foam was custom manufactured for each plenum, a small degree of hand work was required to ensure proper fitment. Furthermore room temperature vulcanizing silicone (RTV) was used at either end of the foam as a means to ensure a proper air seal. The metal foam and woven metal mesh (Rigimesh) are shown in Figure $10^{\dagger \dagger}$.
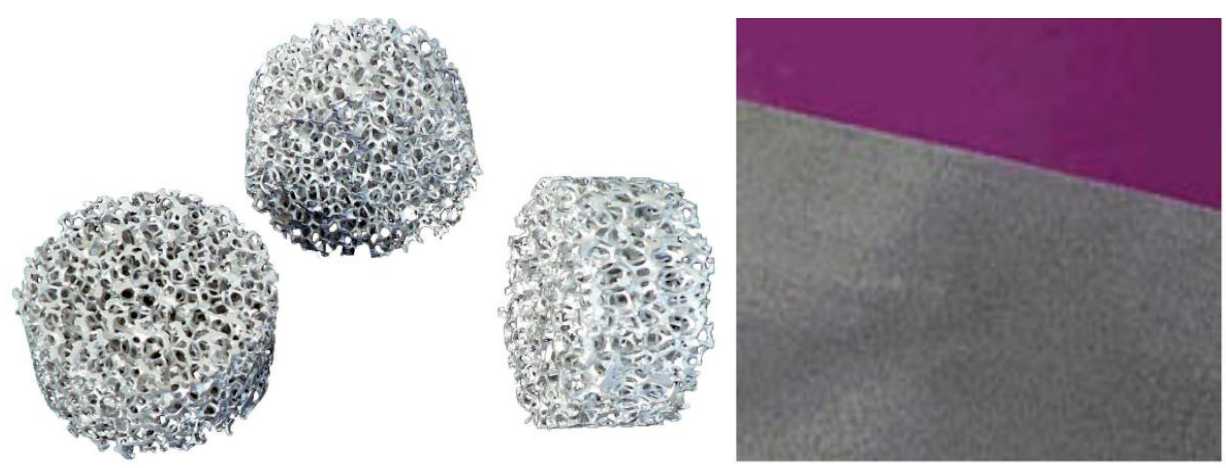

Figure 10. Samples of metal foam and woven metal mesh used in the circulation control plenums ${ }^{\dagger \dagger}$.

\section{B. Rigimesh}

The woven metal mesh in Figure 10 is a product manufactured by Pall Corporation known as Rigimesh. Rigimesh is available in many porosities, and is used widely in the aerospace industry for screening material in wind tunnels. This product was recommended for use in AMELIA's plenums based on its ability to resist flow. Pressure loss calculations based on a simplified version of AMELIA's low pressure system supply geometry, indicated a large difference in pressure being delivered to the inboard and outboard plenums. It was suspected that Rigimesh could be employed to accommodate for the uneven pressure loss created by the differing geometry leading to the inboard and outboard plenums.

\footnotetext{
${ }^{\dagger}$ Images couresty of ERG Aerospace and Pall Corporation.
} 


\section{Slot Flow Calibration Set-Up}

Calibration of AMELIA's slots occurred over a three month period at NASA Ames Research Center's Fluid Mechanics Lab. The wind tunnel model was transported to the FML six months prior to the scheduled wind-on date, in order to provide an assisted check-out and build-up of AMELIA's critical systems. The calibration was a considerable effort requiring an air source capable of delivering $300 \mathrm{CFM}$ at $80 \mathrm{psi}$. In order to achieve the requirements of the model's air supply system, an instrument quality air compressor capable of 1600 CFM at 150 psi was rented. The compressor was placed outside the FML's Test Cell 1, as shown in Figure 11.

A Flow-Dyne critical flow nozzle, with a 1.004" throat diameter, was installed between the compressor and the wind tunnel model as a means of making mass flow rate measurements. The nozzle included an approach tube with taps for upstream temperature and pressure measurements. A second pressure tap (located downstream of the diffuser section) allowed for the verification of the pressure ratio required for critical flow.

In order to choke the flow at the throat, an upstream to downstream pressure ratio of 1.2 was required across the nozzle. The slot flow calibration would require a mass flow rate of $1.4 \mathrm{lb} / \mathrm{m} / \mathrm{s}$, as each wing was calibrated independently. At the typical air supply temperature, this mass flow rate corresponds to an upstream pressure of approximately $77 \mathrm{psig}$. However, due to the flow resistance properties of the treatment being tested in the circulation control plenums, the upstream pressure needed to be raised to nearly 87 psig to maintain the required pressure ratio. This higher upstream pressure forced the calibration mass flow rate to be slightly higher than required (approximately $1.58 \mathrm{lb} / \mathrm{s} / \mathrm{s}$ ). The goal of the calibration - to achieve uniform slot flow-would be minimally effected by the difference in mass flow rate.

Many components, besides the critical flow nozzle, were required including reducers, multiple safety relief valves, and globe valves for flow control. The calibration system schematic can be seen in Figure 12.

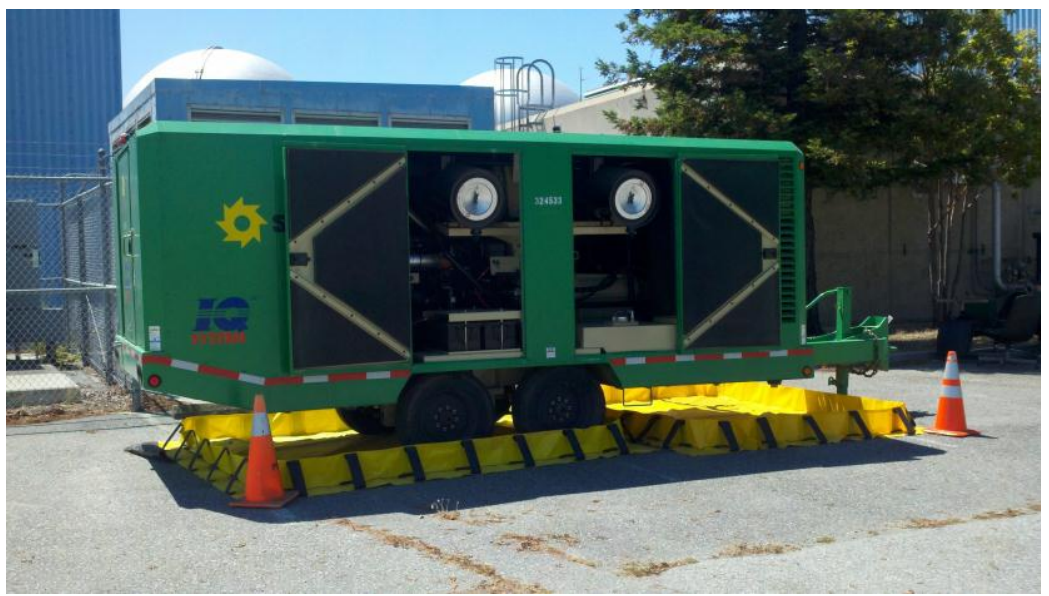

Figure 11. Air compressor used for the slot flow calibration effort.

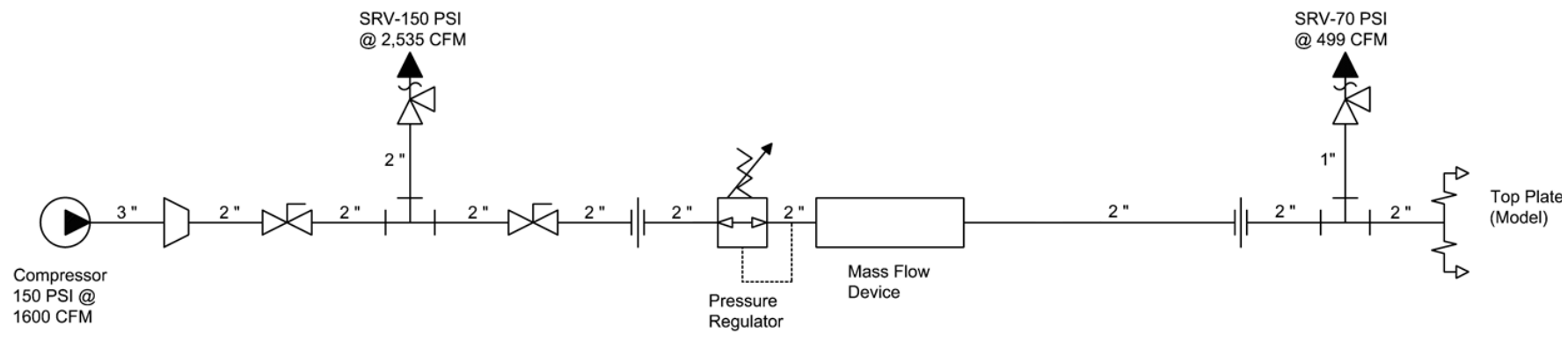

Figure 12. Schematic of the slot flow calibration air delivery system. 
In order to produce realistic flow conditions in the circulation control plenums, air was delivered to the model's low pressure distribution plenum (see the Model Description Section for further details on this plenum). From the low pressure distribution plenum, AMELIA's internal butterfly valves could be used to control the mass flow delivered to each circulation control plenum (this would also provide a check-out of the gear motors used to adjust the butterfly valves). Figure 13 shows the model in Test Cell 1, with the air supply attached to the right wing low pressure distribution plenum. The model was secured to a work table through a metal frame bolted to the model's underside.

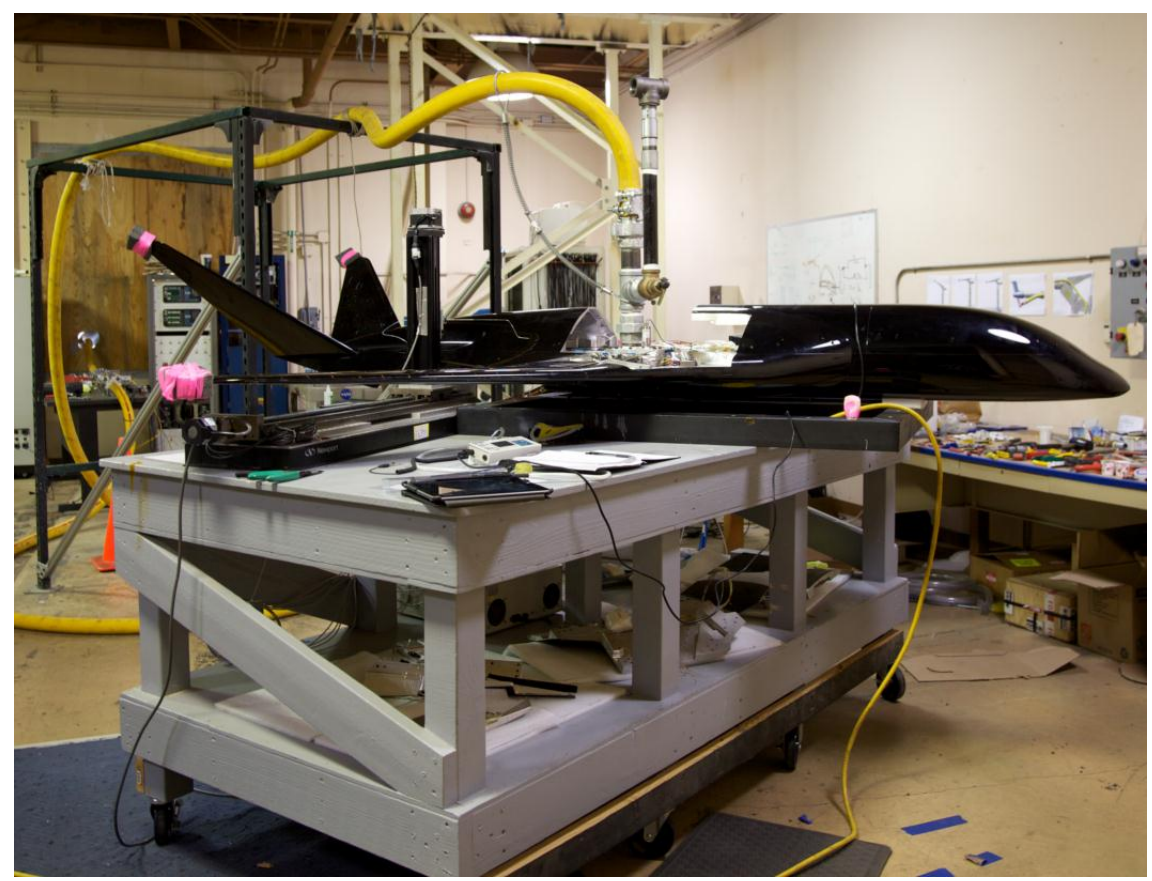

Figure 13. Slot flow calibration set-up with air supply attached at the LPDP.

\section{Oil Flow Visualization Results}

Initial slot flow calibration runs were treated as a means to qualitatively evaluate the safety and performance of the test set-up and model. In regards to the slot flow, these qualitative evaluations typically involved a certain degree of "feeling" the flow, after which it was apparent that there was serious non-uniformity coming from the leading edge slots. Fluorescent tufts were used to further explore the poor flow coming from the slots, however after a few runs it was determined that the tufts lacked the resolution needed to fully visualize the upper surface flow. Pigmented gear oil was later used on the upper surface of the wing as the primary indicator of flow uniformity. The slot flow calibration was performed on the right wing (as shown in Figure 13), as the left wing was instrumented with numerous surface pressure ports that could be compromised by oil. Once acceptable flow uniformity was achieved on the right wing, the plenum treatment would be duplicated on the left wing and checked for symmetry.

\section{A. No Treatment}

As a baseline case, oil flow visualization was performed on the right wing with no flow treatment in the plenums. The effects of the leading edge outboard plenum inlet were clearly present, and extended as far as the trailing edge inboard plenum (as shown in Figure 14). In the absence of flow treatment the plenum does little to create static conditions, allowing the flow to rush out of the slot in the region near the inlet. This was also apparent in the drastically varying readings from the three total pressure probes spanning the plenum chamber. Not shown by the oil is the three dimensionality of the flow. Although the flow remains attached to the upper surface of the wing, swirl and vorticity (presumably created by the pathway to the inlet of the plenum) exist well above the wings upper surface. 


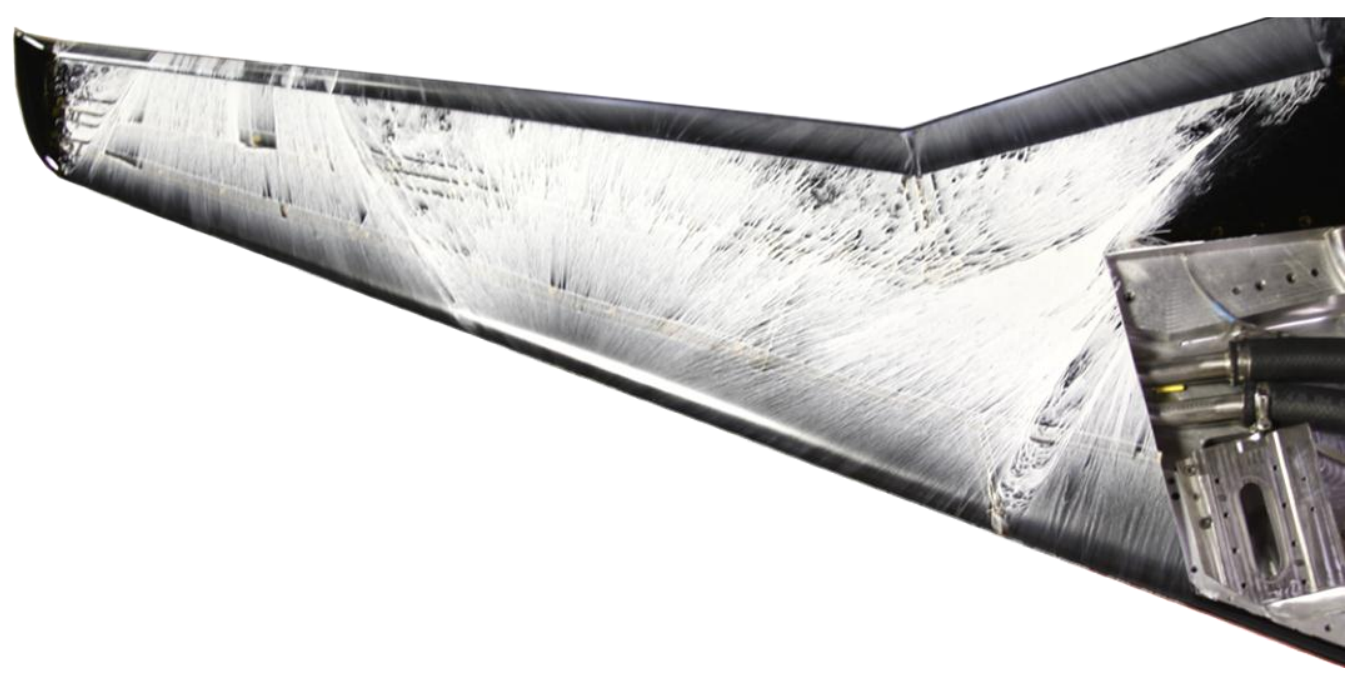

Figure 14. Slot Flow Calibration Oil Flow Visualization: No Plenum Treatment.

\section{B. 6\% Dense Metal Foam}

The first attempt at treating the flow in the plenum began with the lighter of the two metal foam densities. The foam was lightly glued into the premanufactured grooves just upstream (with respect to the circulation control flow direction inside the plenum) of the total pressure probes. The effect of the $6 \%$ dense metal foam can be seen in Figure 15. The region affected by the inlet is clearly diminished, however it remains present. The plenum treatment does create some regions of promise, primarily the areas unaffected by the inlet flow where streamlines remain relatively perpendicular to the leading edge slot. Similarities to the "No Treatment" case were present, in the variance in total pressure probe measurements and three dimensionality of the flow.

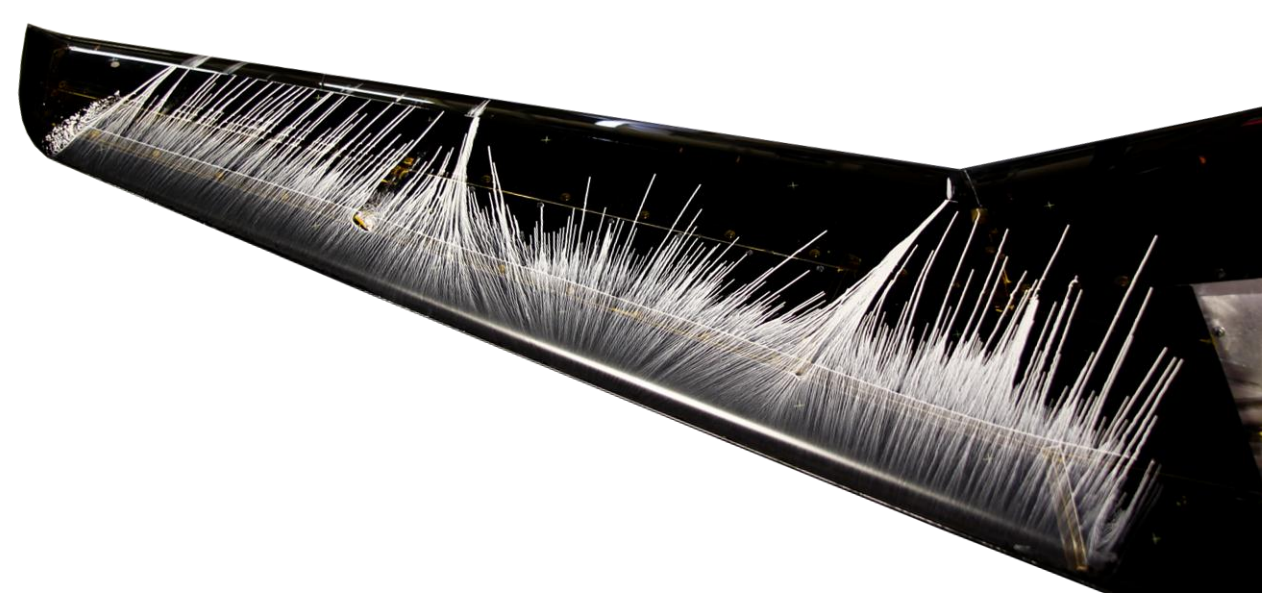

Figure 15. Slot Flow Calibration Oil Flow Visualization: 6\% Dense Metal Foam. 


\section{C. $12 \%$ Dense Metal Foam}

With the few regions of acceptable flow created by the $6 \%$ dense metal foam, there was much anticipation for the success of the $12 \%$ dense metal foam. This foam was installed in the same manner as the $6 \%$, and tested at the same conditions. The oil flow visualization results for the $12 \%$ dense metal foam can be seen in Figure 16. Although the areas of acceptable flow quality have grown slightly, the inlet effects still dominate the flow over the wing. Many of the undesirable pressure qualities remained present with this plenum treatment.

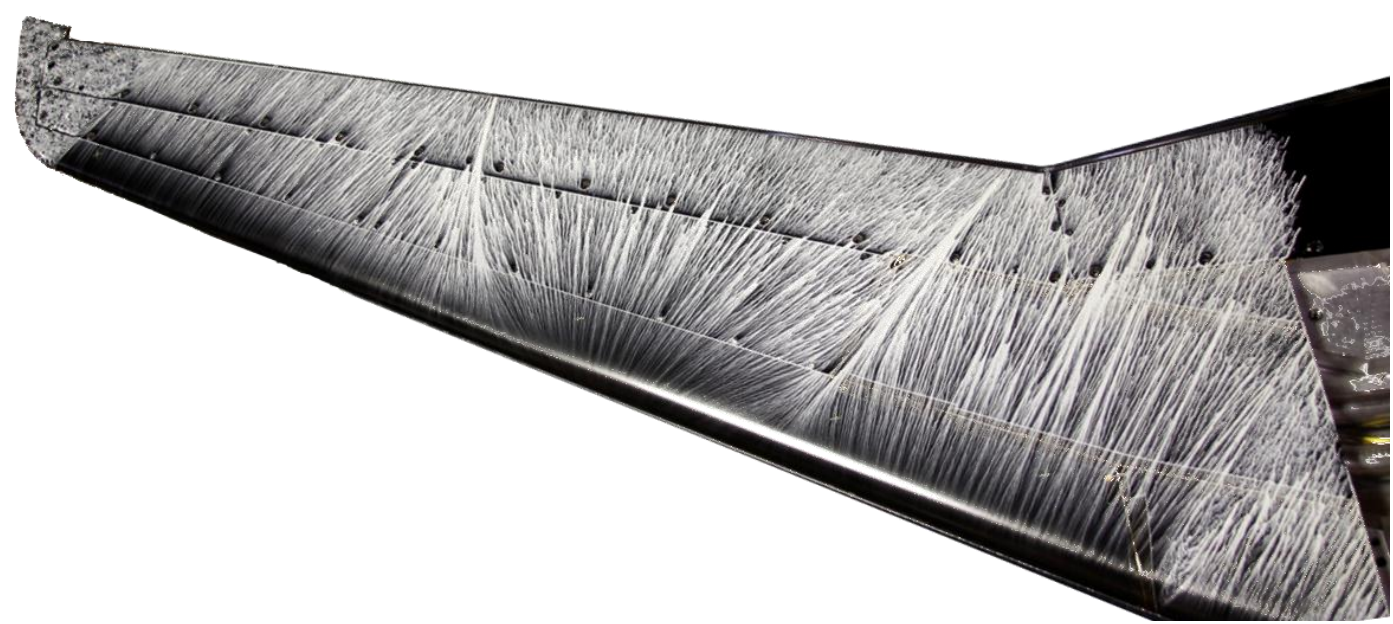

Figure 16. Slot Flow Calibration Oil Flow Visualization: 12\% Dense Metal Foam.

The failure of the $12 \%$ metal foam inspired further investigation of the flow within the plenums. The same pigmented oil applied to the wing upper surface, was then applied inside the LEOB plenum (this was also done during the $6 \%$ dense metal foam runs). The oil flow visualization of the flow within the plenum can be seen in Figure 17. The location of the plenum inlet is near the center of the top figure. The visible oil streaks in the plenum are the attachment lines of the vortices, and serve as further evidence of the existence of highly directional flow in the plenum. As a result of the internal oil flow runs, the focus of the slot flow calibration effort shifted to eliminating the swirled flow in the plenums.

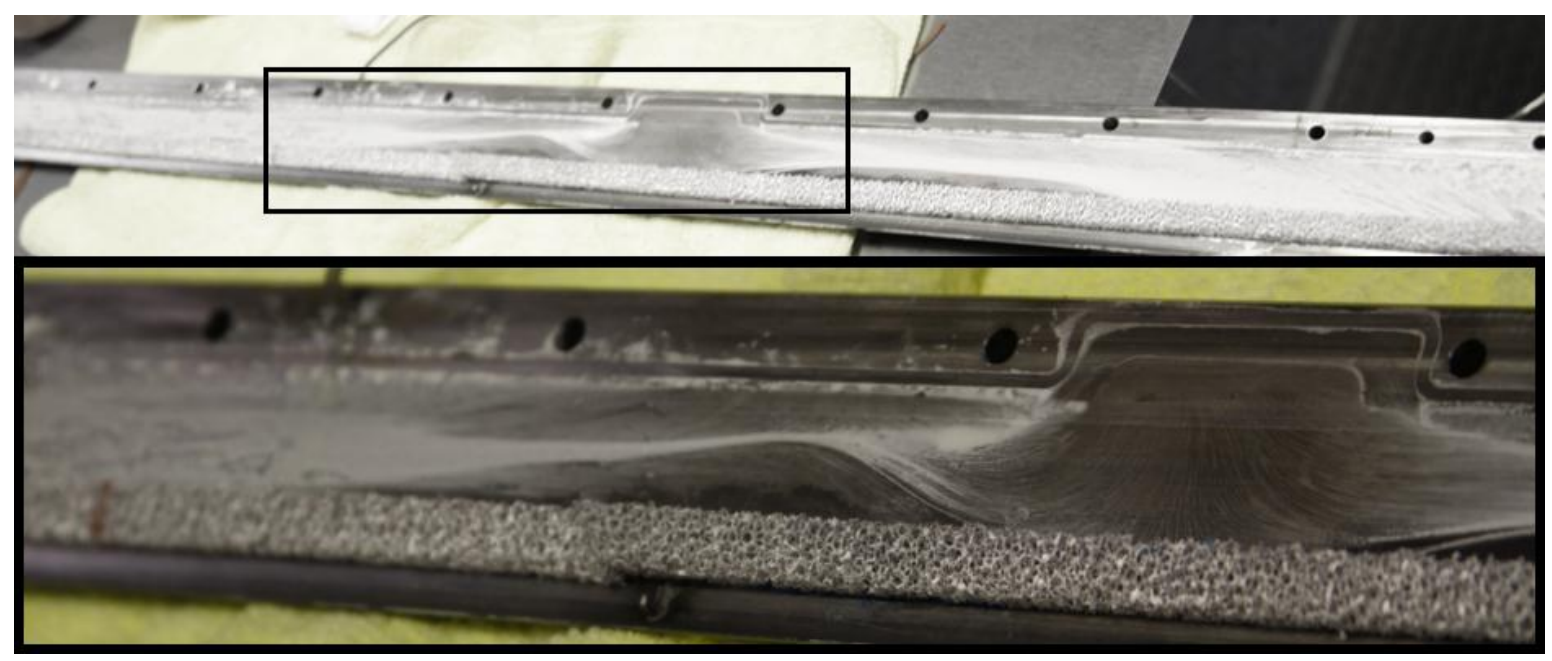

Figure 17. Plenum Internal Oil Flow Visualization. 


\section{Other Plenum Treatments}

The metal foam did succeed in straightening the flow in the regions on either side of the inlet, for this reason many other plenum treatments were testing in combination with the foam. Secondary treatments were tested for the sole purpose of mitigating the vortical flow at the inlet, and thus were implemented only at the plenum inlet (as opposed to the metal foam which spanned the entire plenum length). The first action in mitigating the swirled flow was to smooth the sharp edges of the inlet to each plenum. Additional metal foam, shaped in the form of a wedge, was added to the plenum inlet as one of the first secondary treatments to be tested. The wedge shape and density were altered multiple times before it was ruled out as a treatment. A perforated plate, made from shim stock, was the next test subject. After many iterations of the amount of perforation and layout within the plenum, this treatment was rejected. A rudimentary turning vane was also implemented at the inlet, although (like the other treatments) it altered the flow, the turning vane did little to improve the uniformity. Combinations and variations of these treatments all proved to lessen the effect of the inlet, but not eliminate it.

It wasn't until a small strip of Rigimesh was added to the upstream side of the foam (near the inlet), that the flow began to behave as desired. Until that time, the Rigimesh had not been considered, as it was intended to be implemented near the low pressure distribution plenum to reduce the pressure of the flow being delivered to the inboard plenums.

A summary of the attempts to obtain uniform flow in the leading edge outboard plenum can be seen in Figure 18.

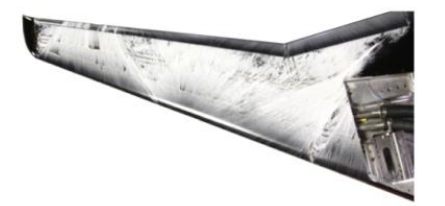

No Treatment

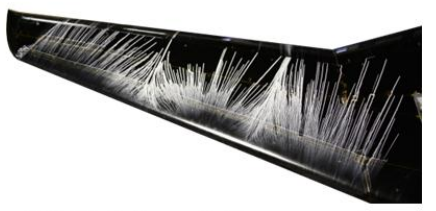

12\% Metal Foam+ Wedge

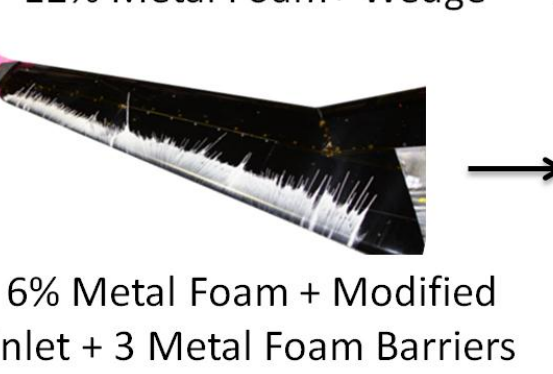

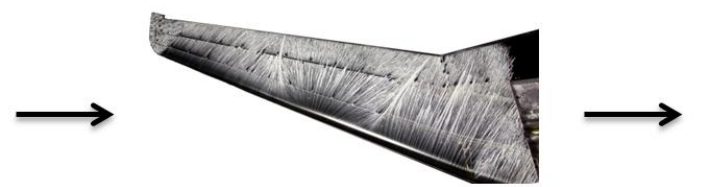

$6 \%$ Metal Foam

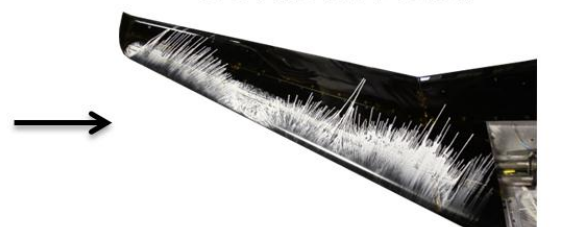

12\% Metal Foam + Modified

Wedge

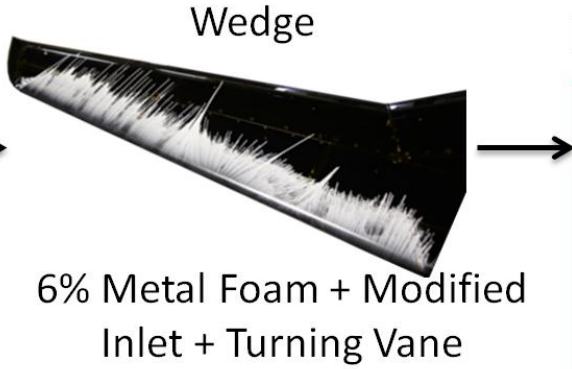

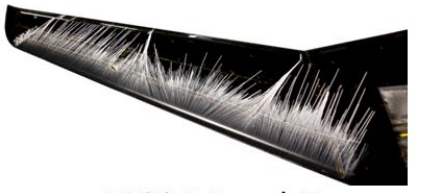

$12 \%$ Metal Foam

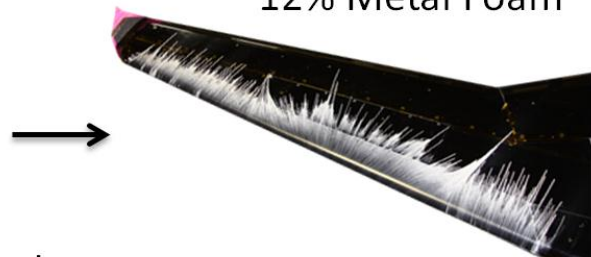

6\% Metal Foam + Modified Inlet +2 Metal Foam Barriers

Figure 18. Slot Flow Calibration Oil Flow Visualization: Summary. 


\section{E. $12 \%$ Metal Foam + Rigimesh}

The $12 \%$ dense metal foam lined with Rigimesh produced uniform slot flow with an acceptable pressure distribution inside the plenum, shown in more detail in Figure 19. Further tuning of the slot flow was accomplished by adjusting the grade, and number of layers of Rigimesh inside each plenum. As mentioned previously, the Rigimesh was intended to be used in the supply pipes branching from the low pressure distribution plenum. In that

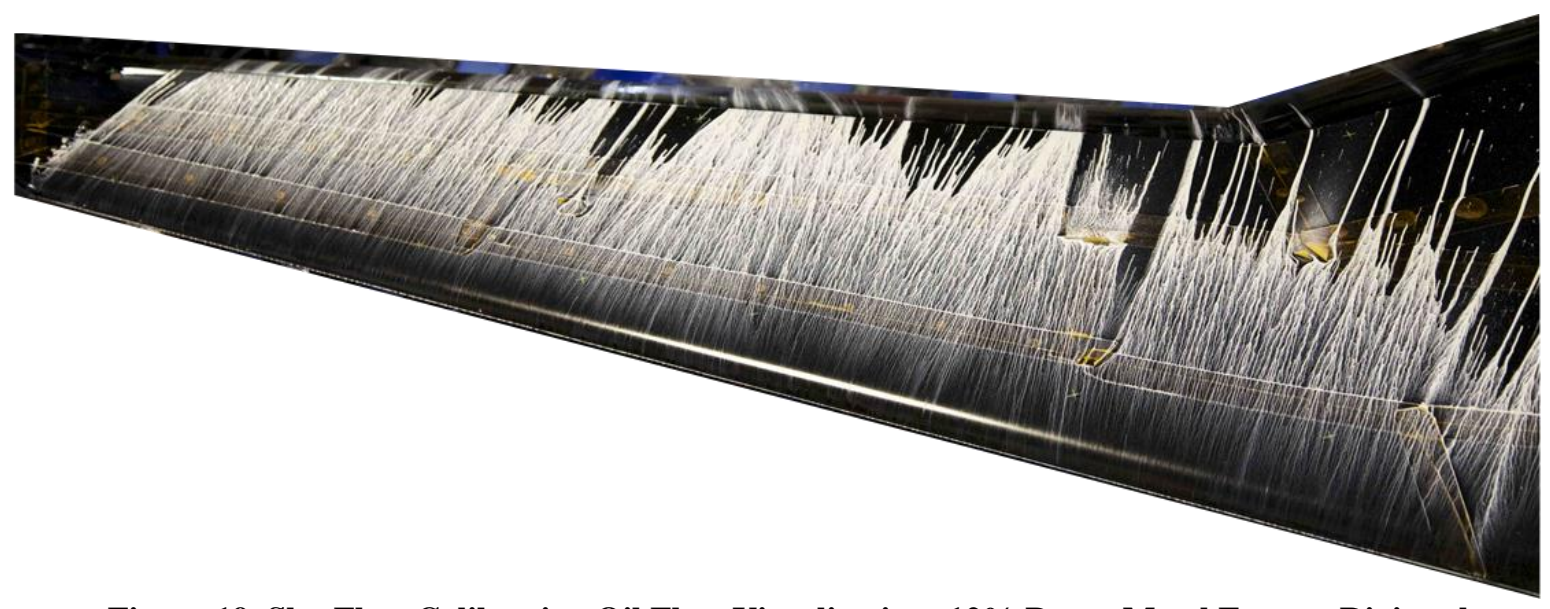

Figure 19. Slot Flow Calibration Oil Flow Visualization: 12\% Dense Metal Foam + Rigimesh.

application, only a small amount of Rigimesh would be needed, therefore only two sheets (9"x9") were purchased. Fortunately, the facility provided an additional roll of Rigimesh of an unknown porosity. Although its exact porosity could not be identified, its performance very nearly matched the grade $\mathrm{J}$ and grade $\mathrm{K}$ being tested. Table 2 outlines the Rigimesh used in the final configuration of each plenum. Both the outboard plenums required a second layer only in the vicinity of the plenum inlet, while the foam in the inboard plenums received two layers over their entirety. The final configuration of both the trailing edge inboard and outboard plenums can be seen in Figure 20.

Table 2. Rigimesh treatment in each plenum.

\begin{tabular}{|c|c|}
\hline Plenum & Rigimesh Type \\
\hline LEIB & $\mathrm{K}, \mathrm{K}$ \\
\hline LEOB & $\mathrm{K}, \mathrm{K}$ \\
\hline TEOB & $\mathrm{J}, ?^{*}$ \\
\hline TEIB & $\mathrm{J}, ?^{*}$ \\
\hline${ }^{*}$ ? represents the unidentified Rigimesh type \\
\hline
\end{tabular}

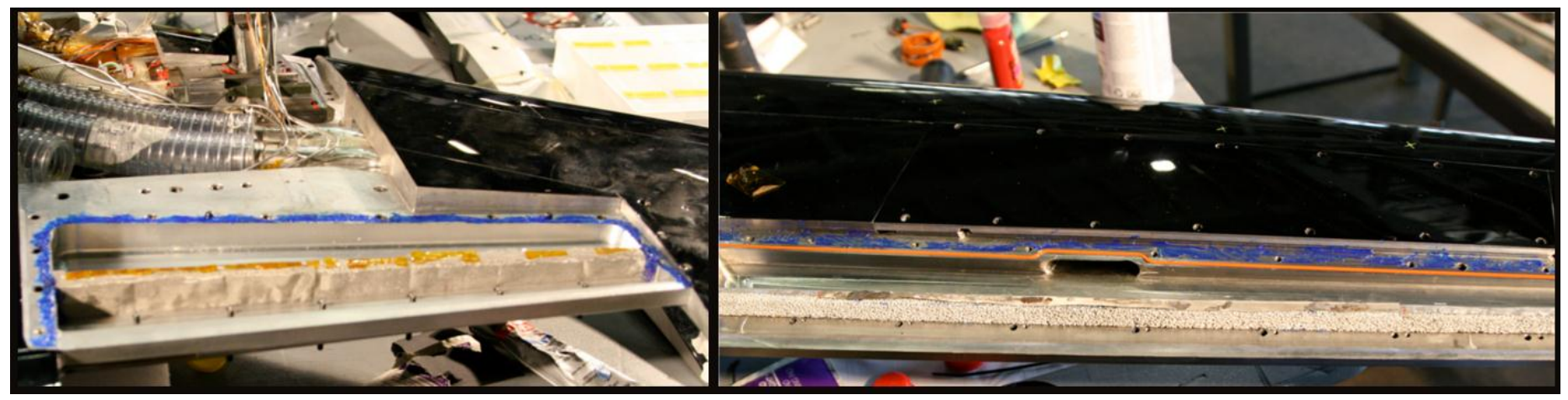

Figure 20. 12\% dense metal foam + Rigimesh in the trailing edge inboard and outboard plenums. 


\section{Slot Height Setting and Verification}

As mentioned previously the design slot height-to-chord ratio differed greatly from the actual slot height-to-chord ratio. With the appropriate plenum treatment in place, and the plenum cover secured, the slot height could be measured and adjusted through the use of the tie-down/set-screw system. Precision measurement of the slot height was of primary importance.

\section{A. Slot Height Measurement}

A hand-held capacitance based gap measurement device was used to obtain values for AMELIA's slot height. The device (borrowed from NASA Langley Research Center) is formally known as the Capacitec Gapmaster3 and when used with the flat-tip, double sided measurement wand has an accuracy of \pm 0.5 mils. The flexible probe was outfitted with a "probe-stop" that ensured the measurement was taken at a constant depth throughout the survey. Some regions of the slot were inaccessible with the probe due to nozzle curvature, in these regions feeler gauges were employed.

The slot height measurement survey consisted of documenting the slot height in each plenum prior to the wind tunnel test, during the test, and after the test. It also includes a limited dataset of pressurized (circulation control on) versus static (circulation control off) slot height measurements.

\section{B. Slot Setting Accuracy}

The trailing edge slot height was set according to the slot height-to-chord ratio mentioned previously. Although the tie-down/set-screw system worked well overall, some regions - primarily near the ends of the plenum-proved more stubborn than others. A comparison of the actual slot height to the ideal slot height for each wing is shown in Figure 21. The edges of the outboard plenum depart from the ideal curve by nearly 8 mils in some places, however effects from this departure can be considered extremely local. The difference was caused by the inability of the tiedown to overcome the local stiffness of the plenum cover. In one case (as shown at the inboard-most measurement of the left wing's outboard plenum) attempts to further tighten the cover resulted in a permanent tie-down failure. 


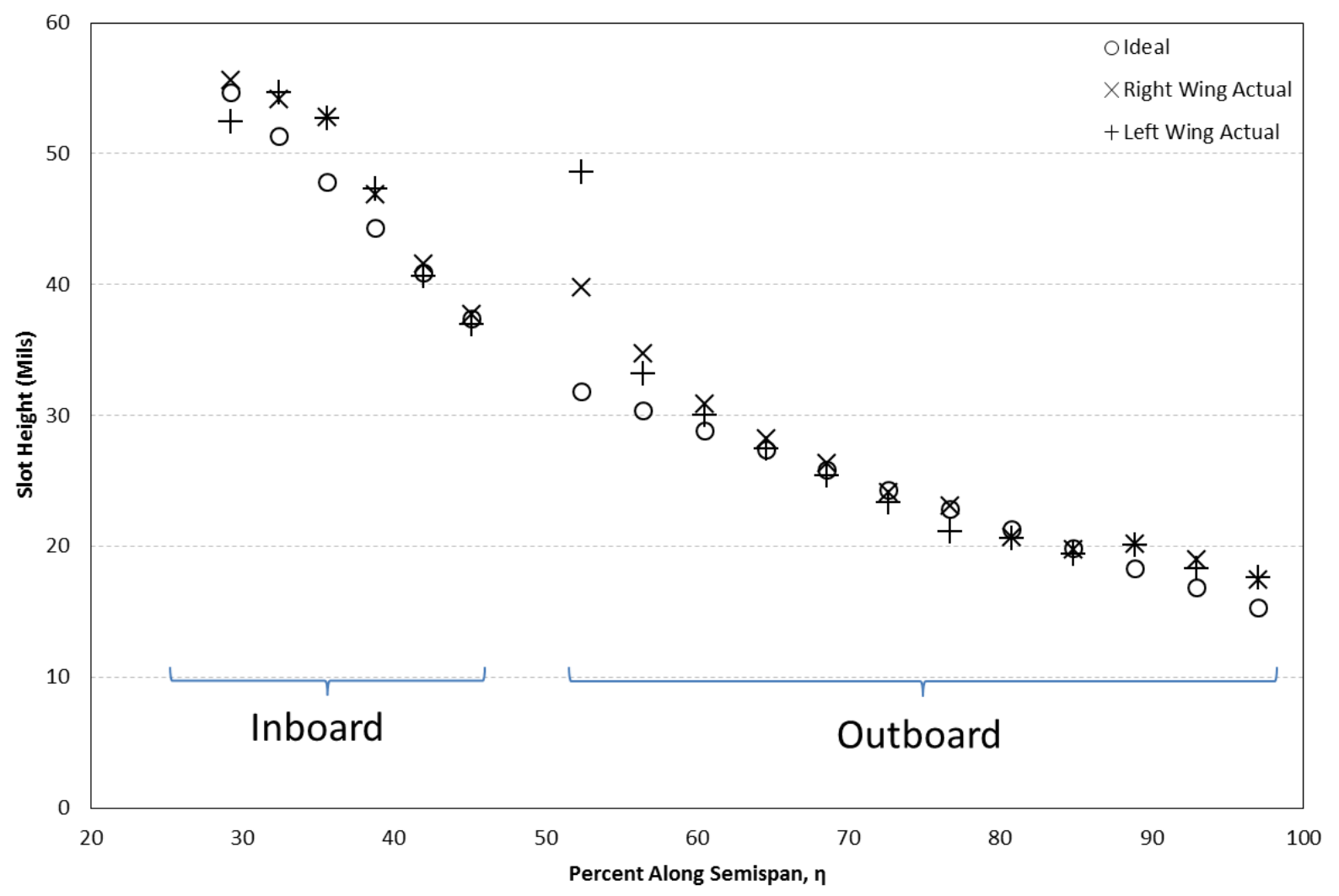

Figure 21. Actual Slot Height vs Ideal Slot Height.

The actual slot height values were used to calculate a new slot height-to-chord ratio, as well as a new slot height to radius ratio. These values are shown in Table 3, and were used to verify agreement between the test configuration and the original (ideal) design configuration from Year 1 of the NRA. The $6 \%$ difference in actual vs. ideal slot height to chord ratio was deemed acceptable.

Table 3. Design parameters-as measured.

\section{Design Parameters}

\begin{tabular}{|l|l|l|}
\hline & Ideal & Actual \\
\hline $\mathbf{h}_{\text {slot }} / \mathbf{c}$ & 0.00238 & 0.00252 \\
\hline $\mathbf{h}_{\text {slot }} / \mathbf{r}$ & 0.049 & 0.052 \\
\hline
\end{tabular}




\section{Pressurization Effects}

Past circulation control experiments have outlined the importance of documenting the behavior of the slot height under pressure. During pressurization, a small change in the slot height could have serious consequences in the uncertainty associated with the calculation of the discharge coefficient. An investigation into the effect of pressurizing (turning on circulation control flow) the plenum was conducted using the trailing edge of the right wing. The experiment was performed prior to the wind tunnel test, using the existing setup from the slot flow uniformity work. The comparison between static and pressurized slot height for the right wing trailing edge can be seen in Figure 22.

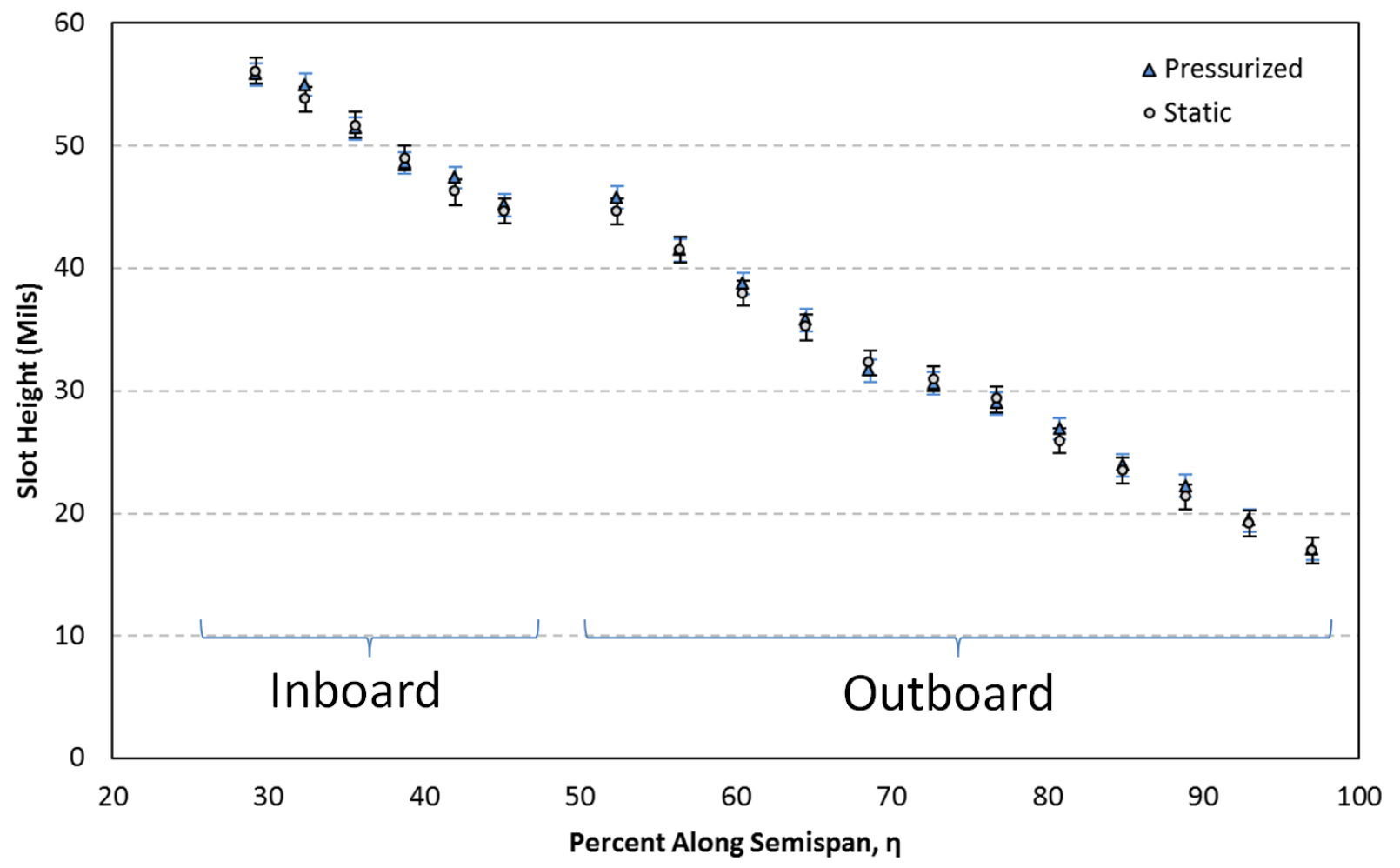

Figure 22. Pressurized vs Static Slot Height.

The $95 \%$ confidence interval for the static slot height measurements is \pm 1.1 mils, and for the pressurized slot height measurements is \pm 0.9 mils. Of primary significance is the scatter of the data falls within the error of the measurement. This verifies the success in setting and securing the slot height using the set-screw/tie-down system. The success of the system in restraining expansion during pressurization severely reduces the time required to take slot height measurements, as the measurements could instead be made statically. Static slot height measurements were preferred as they greatly reduced the risk of damaging the delicate Gapmaster probe. Further measurements including those for the left wing, and the pretest, during test, and posttest slot height datasets were obtained under static conditions. 


\section{Slot Height Symmetry}

Establishing symmetric circulation control flow was a primary concern during the slot flow calibration. Although the plenum treatment plays a significant role in establishing symmetric flow, the slot height setting is considered just as (if not more) important for its ability to locally effect the flow. Every effort was expended in adjusting the slot height to match across wings, however in some locations slight differences exist due to local material strength differences, or lack of resolution in the set-screw/tie-down adjustment method. A comparison between the wings at the leading edge is presented in Figure 23 and Figure 24, where uncertainty for a 95\% confidence interval is \pm 1.1 mils for each wing.

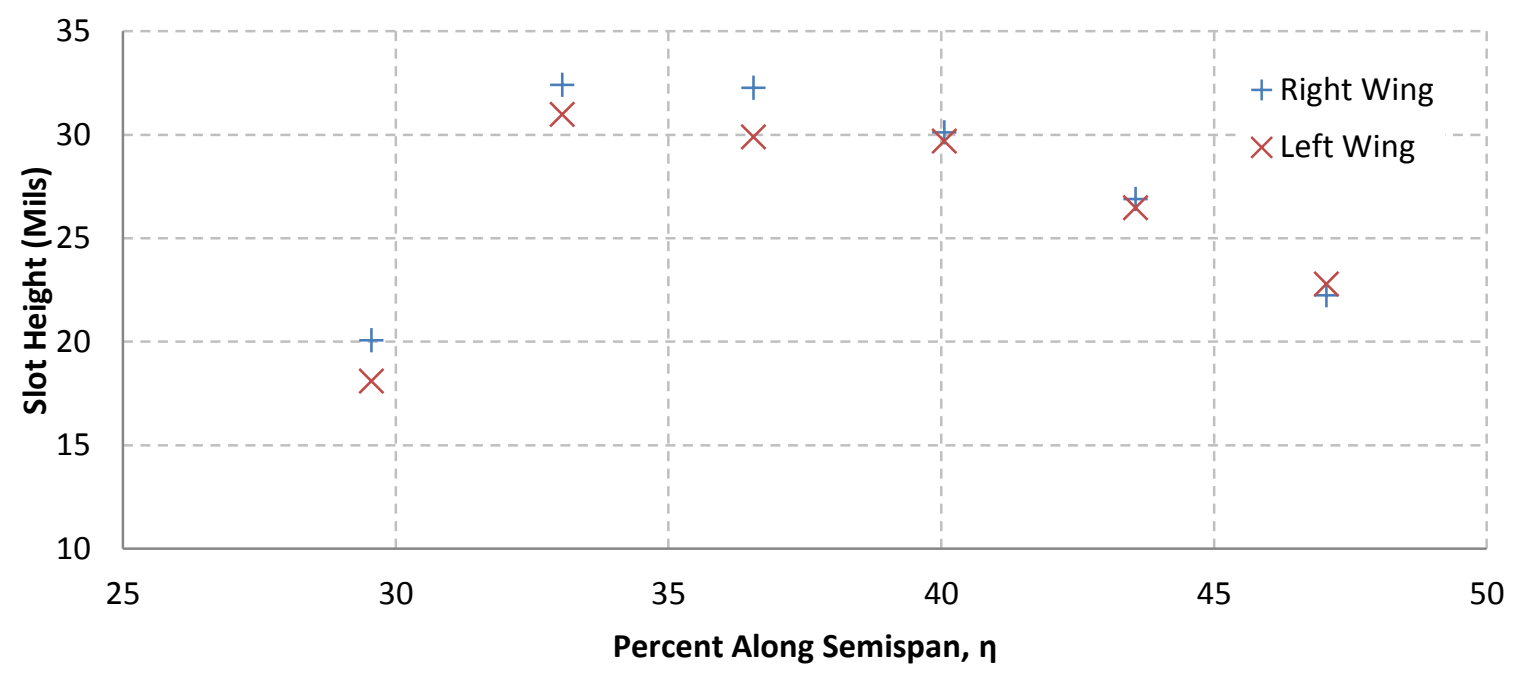

Figure 23. Leading Edge Inboard Plenum left and right wing slot height comparison.

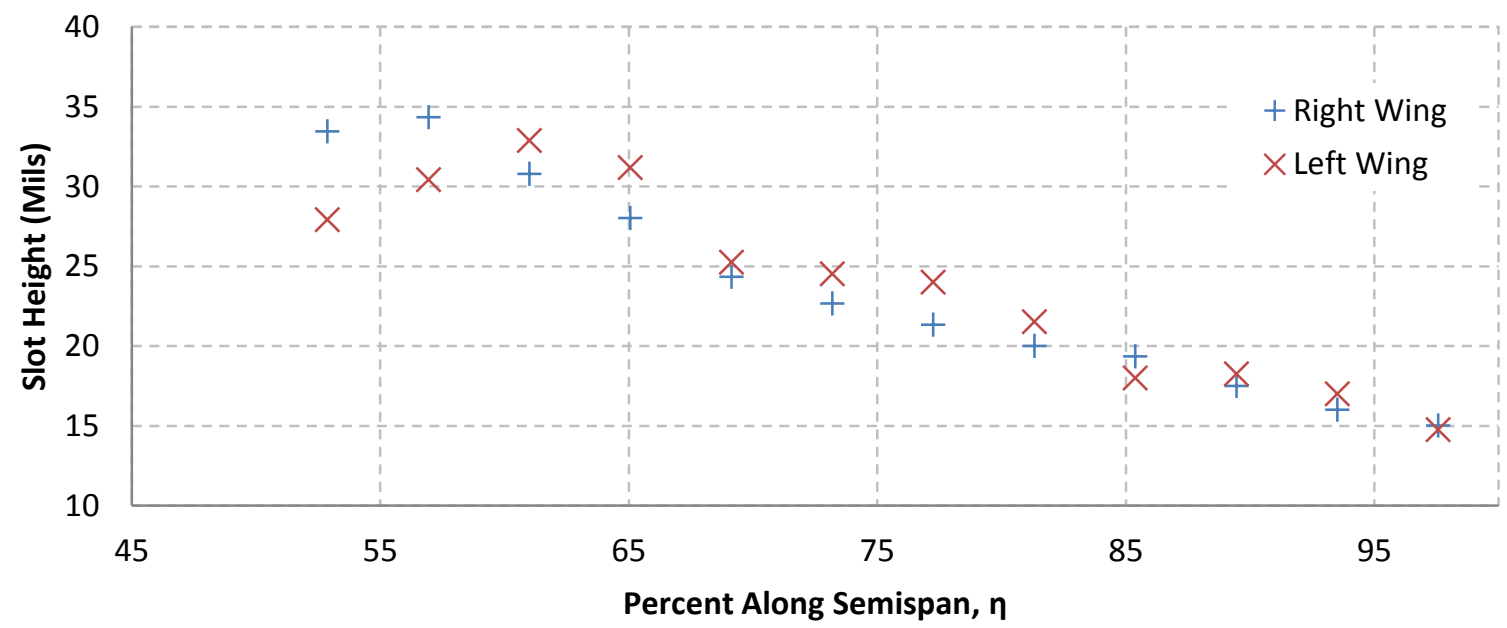

Figure 24. Leading Edge Outboard Plenum left and right wing slot height comparison. 
The leading edge inboard plenum matched well, with only a few locations on the left wing a few mils different from the right wing. The outboard plenum, however, differs by as much as 5 mils in some places. Although this difference is undesired, little could be done as the leading edge plenums are not adjustable.

A comparison of the trailing edge slot heights between the left and right wings can be seen in Figure 25 and Figure 26 , where the $95 \%$ confidence interval uncertainty is \pm 1.1 mils for each wing.

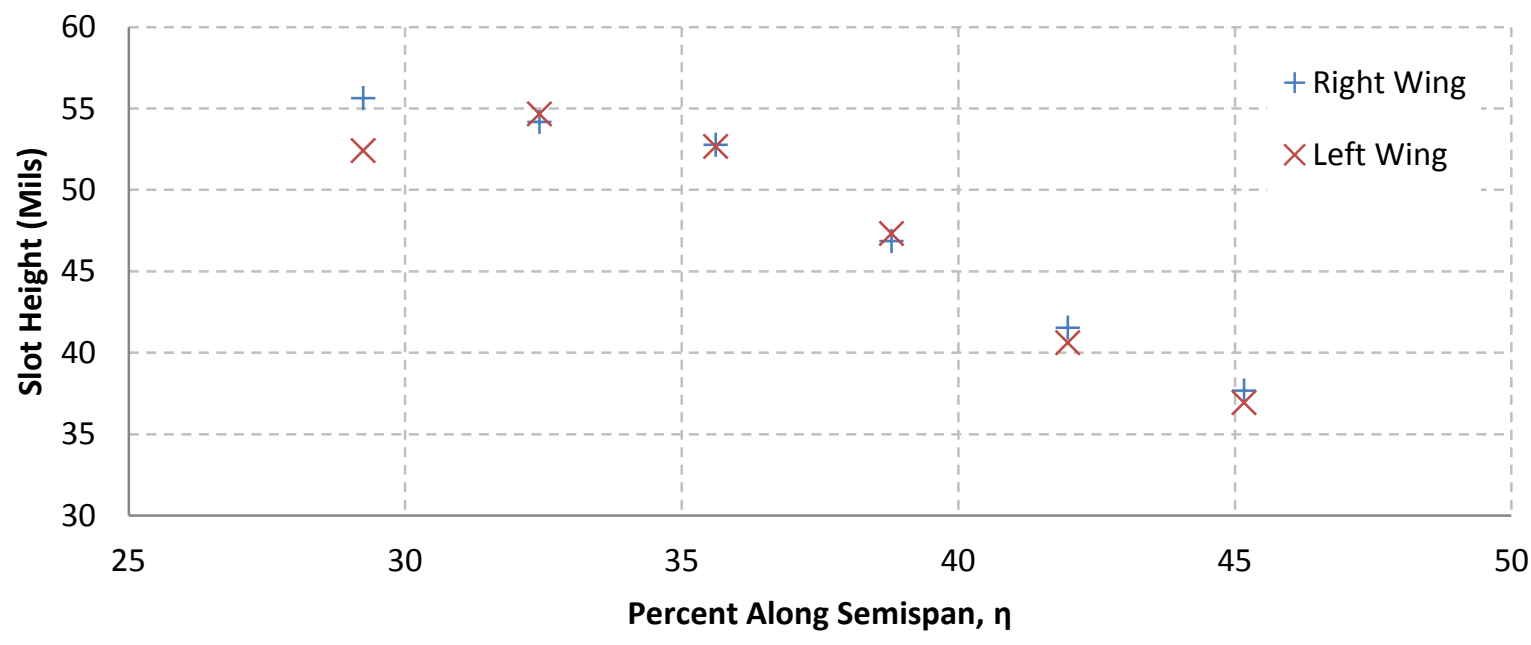

Figure 25. Trailing Edge Inboard Plenum left and right wing slot height comparison.

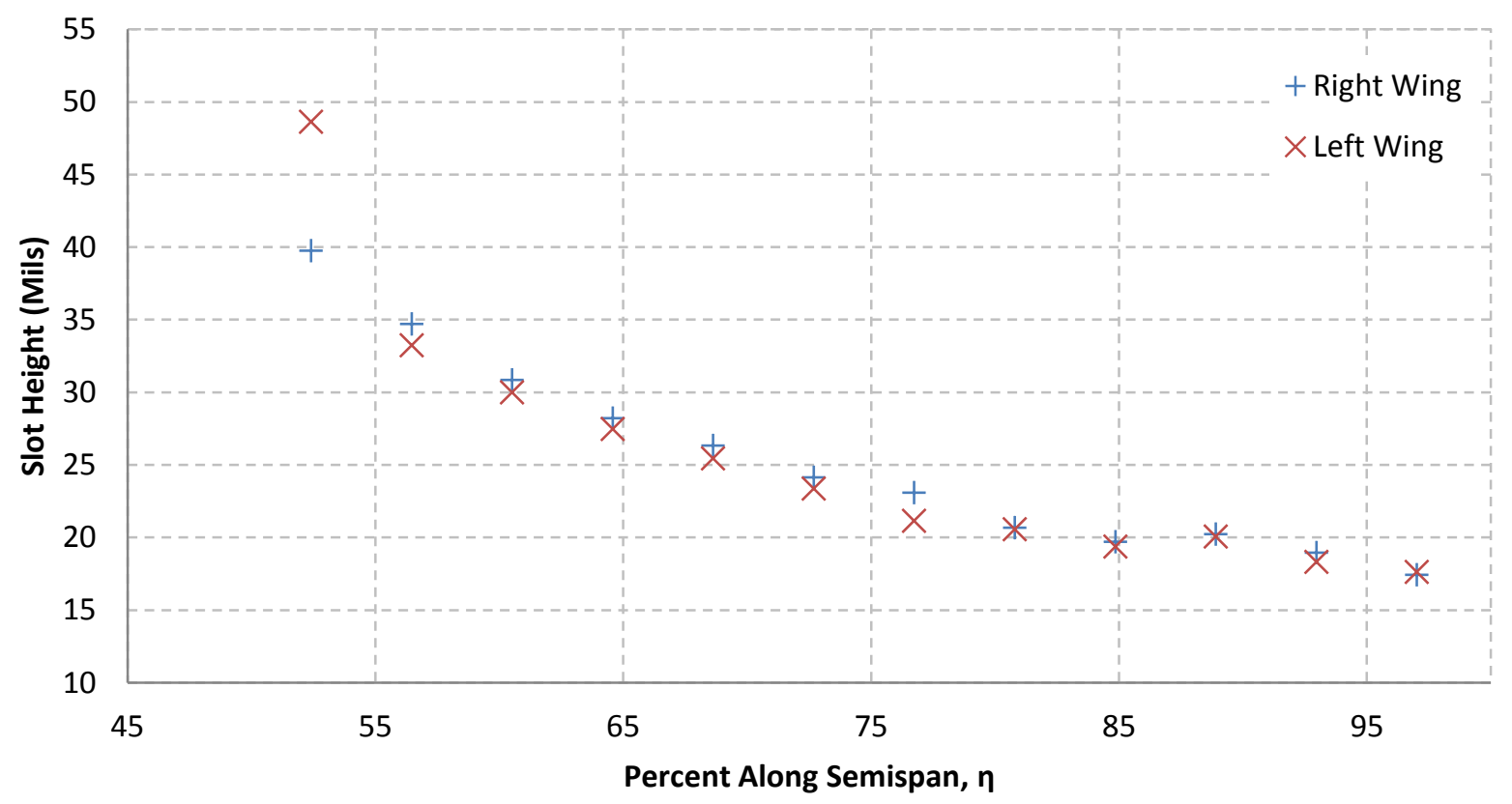

Figure 26. Trailing Edge Outboard Plenum left and right wing slot height comparison. 
Adjustment through the set-screw/tie-down system allowed for much better agreement between the left and right wing trailing edge slot heights. One difference of 3 mils exists at the inboard most station on the inboard plenum. At this location the cover material is at its thickest and adjustments are difficult. At the same location on the outboard plenum of the left wing a tie-down was tightened beyond its ability and permanent damage to the system at this station occurred. The effect of the broken tie-down was deemed minimal and very localized as an adjacent station was only 1" away.

The success in establishing slot height symmetry permitted the permanent fastening of each plenum and setscrew/tie-down station.

\section{Total Pressure Survey}

The pigmented oil provided a qualitative means to verify flow uniformity and flow symmetry across wings, however a quantitative comparison was also desired. The small scale of the measurements limited the type of instrumentation to hot wires or total pressure probes. The total pressure probe was the selected measurement device as it was widely available and robust enough to withstand the harsh measurement environment.

\section{A. Survey Set-Up}

A total pressure probe with a 0.020 " diameter tip was mounted on a LabView controlled 2-axis traverse. The traverse was fixed to a table which was oriented parallel to the slot to be scanned. The flaps were removed to permit the full range of motion of the traverse. The leading edge inboard plenum could not be traversed due to the calibration set-up - the connection at the low pressure distribution plenum prevented the upper surface skin from being attached. At the leading edge outboard slot a total pressure survey was conducted. The measurement could not be made at the slot face, but was instead made on the upper surface of the wing at roughly $20 \%$ chord. The total pressure survey set-up is shown in Figure 27. For all total pressure surveys, a mass flow rate of $1.59 \mathrm{lbm} / \mathrm{s}$ per wing was used to reflect the Full circulation control case to be used during the wind tunnel test.

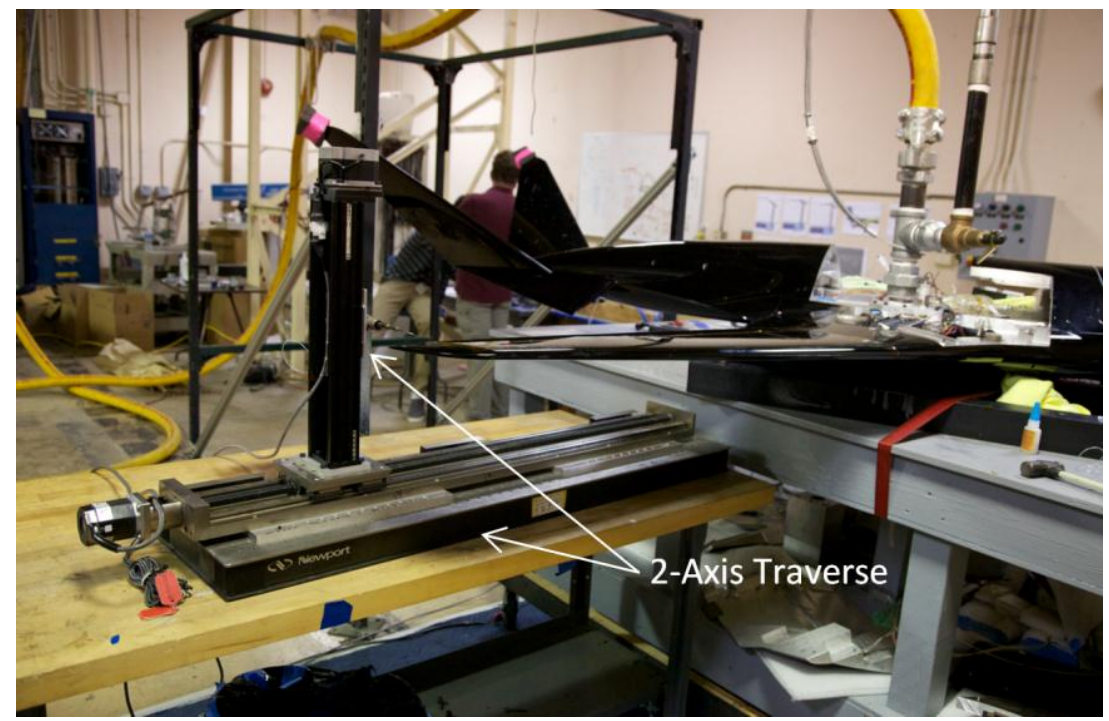

Figure 27. Total pressure survey set-up at the right wing trailing edge slot. 


\section{B. Survey Results}

The total pressure profiles for the right wing's trailing edge inboard plenum are presented in Figure 28. The profiles were recorded at various locations along the span of the plenum, these are indicated by the station number shown in the legend. (Table 4 provides a quantification of the station number as a percentage along the span of the individual plenum.) The vertical axis represents jet width and is presented in inches from the jet centerline. Total pressure can be read from the horizontal axis in psid. The measurements presented in the figure were taken roughly 60 thousandths of an inch from the slot face. As expected the highest total pressure occurs at the inboard most station where the slot height is greatest. The pressure continues to decrease as the probe travels outboard and the slot height tapers. The traverse grid was not sufficiently able to capture the total pressure at the bottom portion of the jet for the two most inboard stations, however the trend of the outboard stations indicates the expected behavior of the pressure returning to zero. These profiles correlate well with the internal pressure probes, and indicate that there are no problem areas in the TEIB plenum.

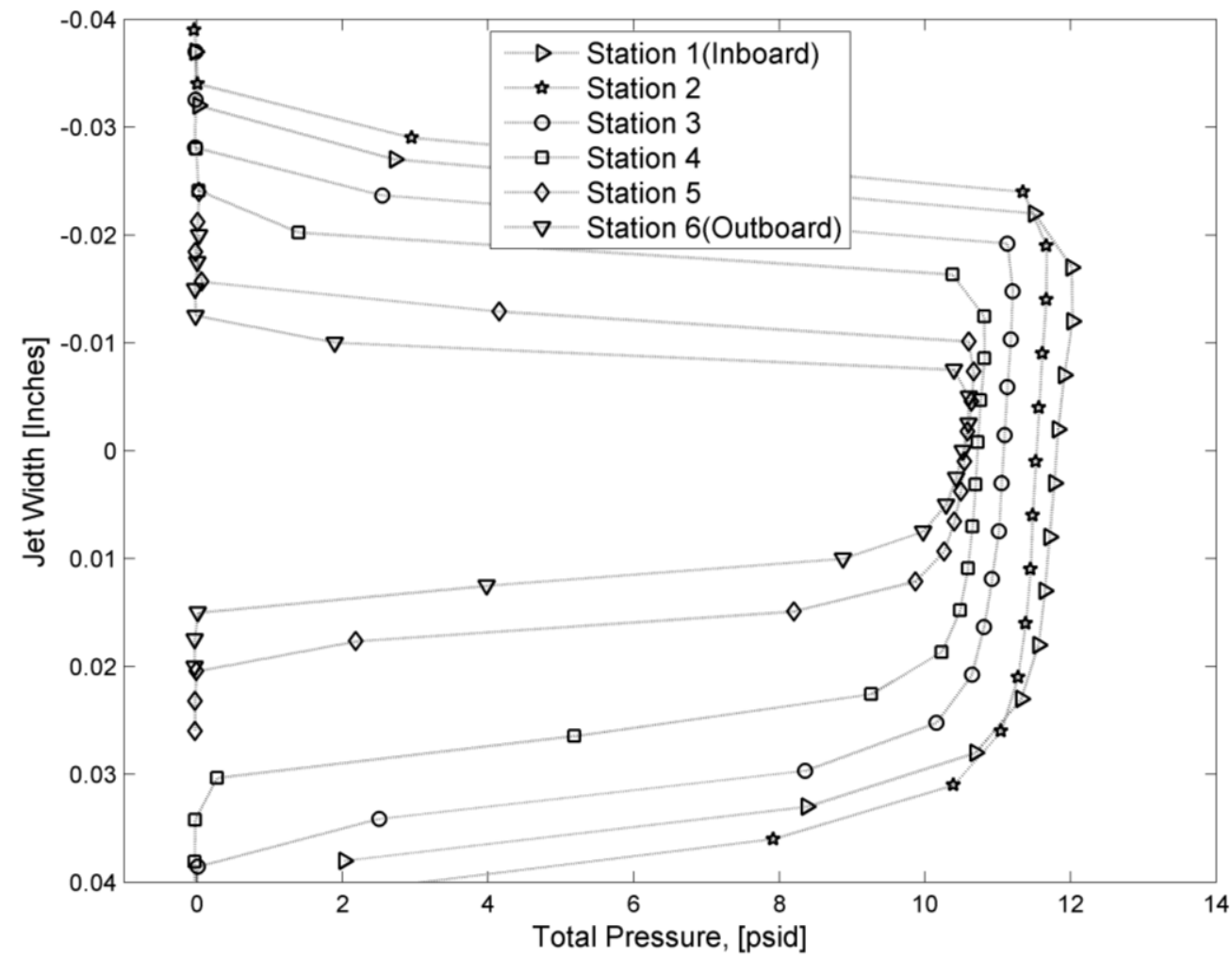

Figure 28. Right wing trailing edge inboard total pressure.

Table 4. Station as percent plenum span(TEIB).

\begin{tabular}{|c|c|}
\hline Station Number & Percent Along Span \\
\hline Station 1 & $2 \%$ \\
\hline Station 2 & $23 \%$ \\
\hline Station 3 & $45 \%$ \\
\hline Station 4 & $68 \%$ \\
\hline Station 5 & $90 \%$ \\
\hline Station 6 & $99 \%$ \\
\hline
\end{tabular}




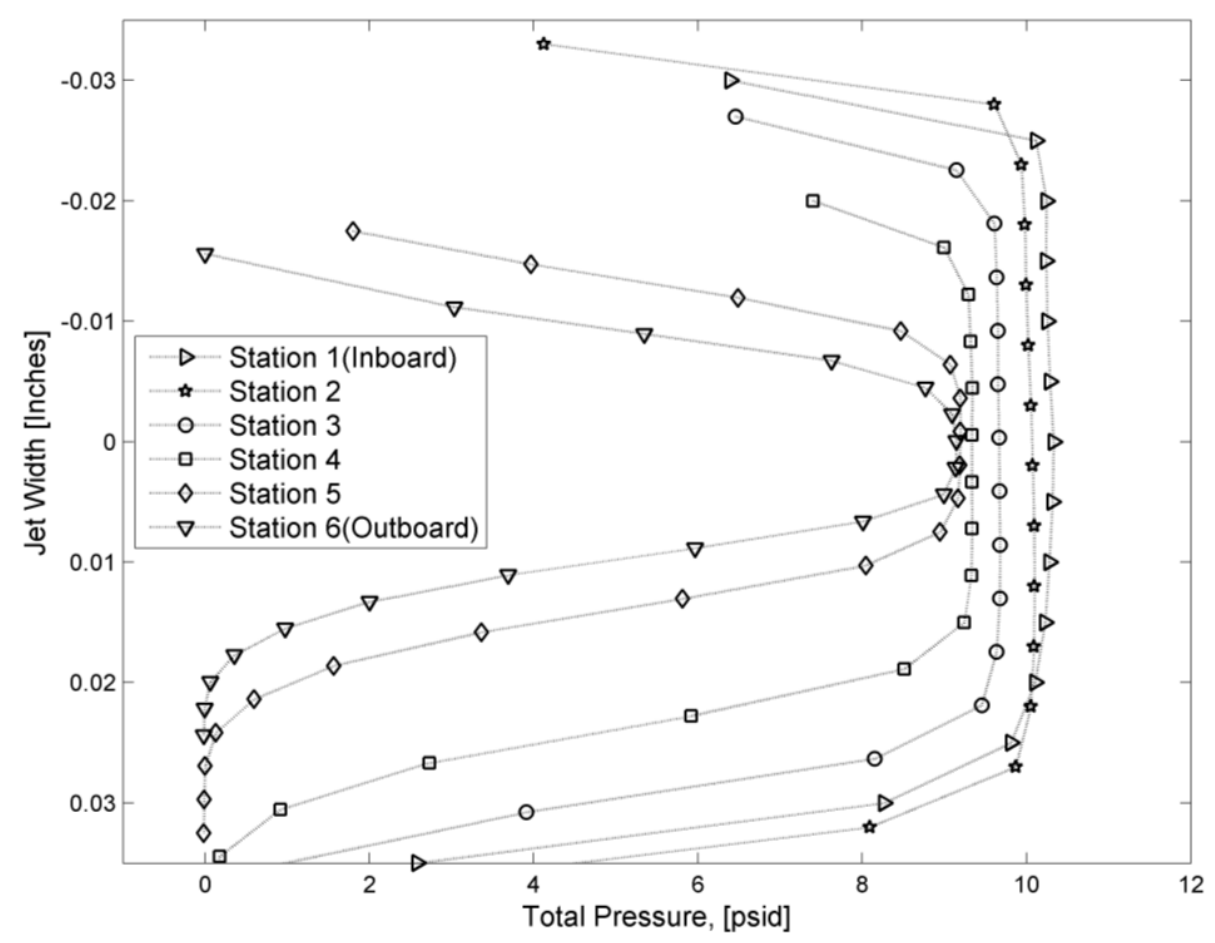

Figure 29. Left wing trailing edge inboard total pressure.

The corresponding total pressure survey for the left wing is shown in Figure 29 (the legend corresponds to the same values in Table 4). The maximum total pressure is achieved at the inboard most station as expecected, however it is nearly 2 psi less than the maximum of the right wing. This is most likely due to a difference in the alignment of the traverse. It was very difficult to align the traverse on the left wing precisely how it had been on the right, primarily due to the traverse/model frame interference. It is suspected that as the probe head traveled outboard, it also traveled slightly away from the slot face, causing the decayed profiles shown at the outboard stations. The profile shape and pressure readings are consistent with jet decay theory. Unfortunately, this survey did not capture the upper portion of the jet, however the trend indicates the total pressure returns to zero.

A survey of the right wing trailing edge outboard plenum (shown in Fig. 30) shows similar rounded profiles. These decayed profiles were expected as the probe was traversed roughly 5 probe diameters from the jet exit, and the average internal pressure of the outboard plenum was less than that used for the inboard surveys. There is greater total pressure variation along the span of this plenum due to plenum length and sensitivity to the decreasing nominal slot height. The profiles at stations 3 and 4 have the least total pressure, which is likely due to the additional plenum treatment required to diffuse vorticity associated with the plenum inlet. Although ideally these profiles would align as well as those from the trailing edge inboard plenum, these were found to be sufficient given that the flow directionality issues had been solved. Total pressure profiles for the corresponding plenum on the left wing were recorded and verified against these measurements. The left wing data trends matched well with those shown here.

Table 5. Station as percent plenum span (TEOB).

\begin{tabular}{|c|c|}
\hline Station Number & Percent Along Span \\
\hline Station 1 & $3 \%$ \\
\hline Station 2 & $23 \%$ \\
\hline Station 3 & $42 \%$ \\
\hline Station 4 & $61 \%$ \\
\hline Station 5 & $80 \%$ \\
\hline Station 6 & $98 \%$ \\
\hline
\end{tabular}




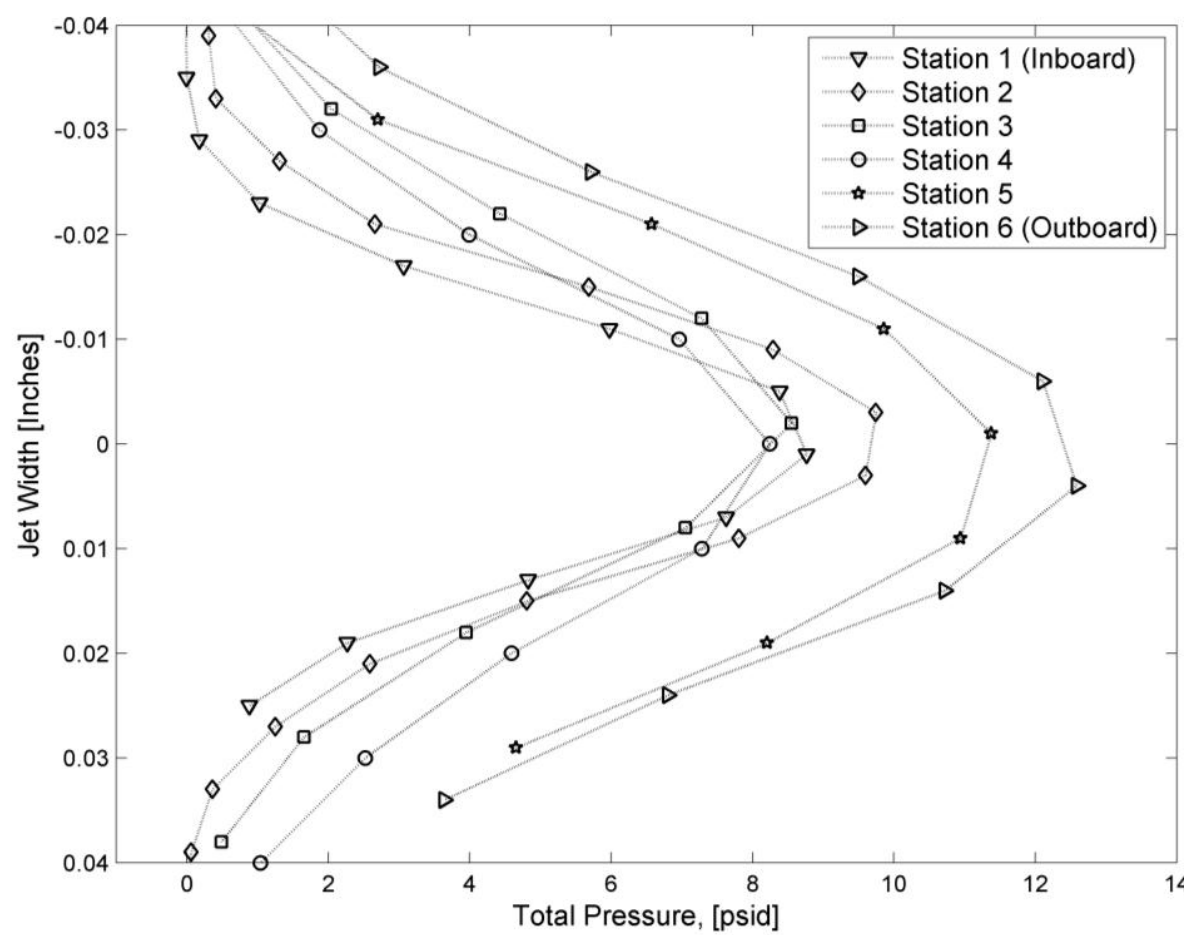

Figure 30. Right wing trailing edge outboard total pressure.

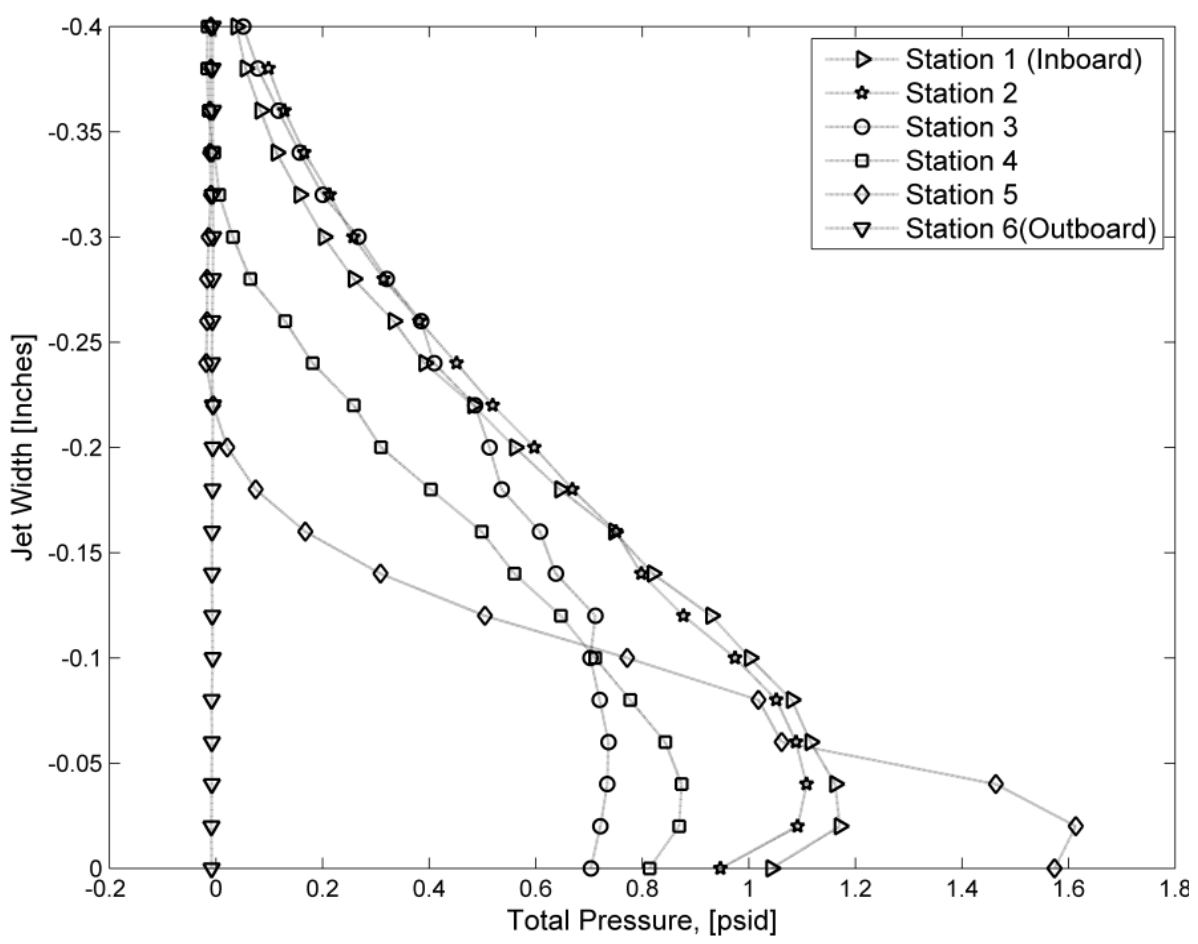

Figure 31. Right wing leading edge outboard total pressure.

An upper surface survey, showing the jet decay from the leading edge slot, is presented in Fig. 31. As mentioned in the previous section, surveys of this type were taken along the $20 \%$ chord line, and relied on the Coanda effect of the leading edge curvature to deliver each jet profile. The 20 thousandths (od) diameter probe was unable to resolve total pressure close to the wall, however the profiles show good agreement along the span, given the distance from the jet. Similar to the behavior of the trailing edge outboard plenum, at the leading edge mid span 
region (stations 3 and 4), there is a slight loss of pressure due to the second layer of Rigimesh required near the plenum inlet. The profile at station 5 has the greatest maximum total pressure this is most likely a result of the orientation of the traverse and slightly higher pressure at the end of the plenum (similar to that at the trailing edge outboard plenum). Station 6 captured no profile and was beyond (outboard) the influence of the leading edge plenum. When repeated on the left wing, the survey showed good agreement.

Table 6. Station as percent plenum span (TEOB).

\begin{tabular}{|c|c|}
\hline Station Number & Percent Along Span \\
\hline Station 1 & $1 \%$ \\
\hline Station 2 & $14 \%$ \\
\hline Station 3 & $28 \%$ \\
\hline Station 4 & $57 \%$ \\
\hline Station 5 & $86 \%$ \\
\hline Station 6 & $101 \%$ \\
\hline
\end{tabular}

\section{Conclusion}

The work conducted at the Fluid Mechanics Lab in preparation for the wind tunnel test was invaluable to the success of the test. Figure 32 shows the results of an oil flow visualization run at the NFAC during the experiment. The circulation control flow streamlines show the successful application of the final plenum treatment configuration. The treatment was evaluated periodically throughout the test and proved to remain effective despite the many wind-on hours. Having achieved directionally uniform slot flow streamlines, the wind tunnel test data can be relied upon as a valid representation of the circulation control concept.

The effort to document the related slot details-slot height, expansion effects, and total pressure surveys-will serve as useful references for comprehensive analysis in the future.

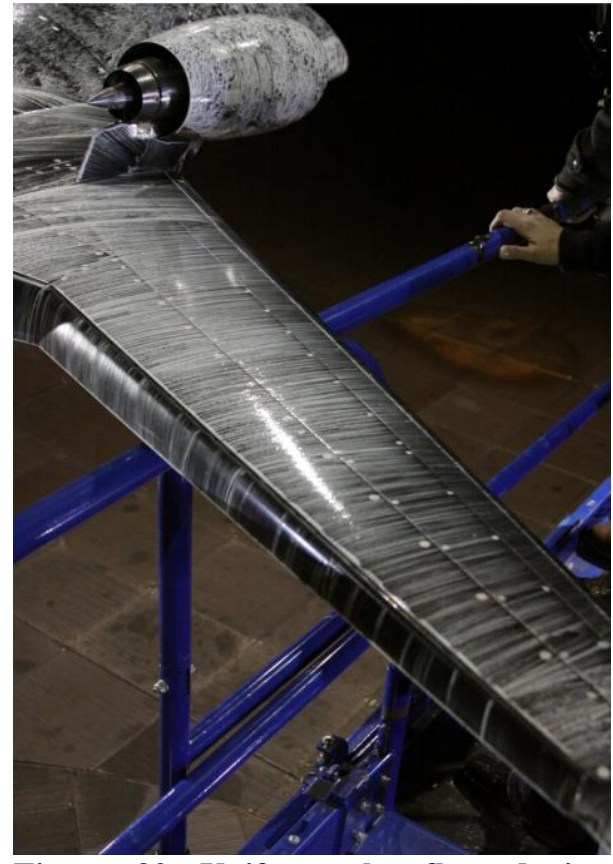

Figure 32. Uniform slot flow during wind tunnel test. 


\section{Appendix}

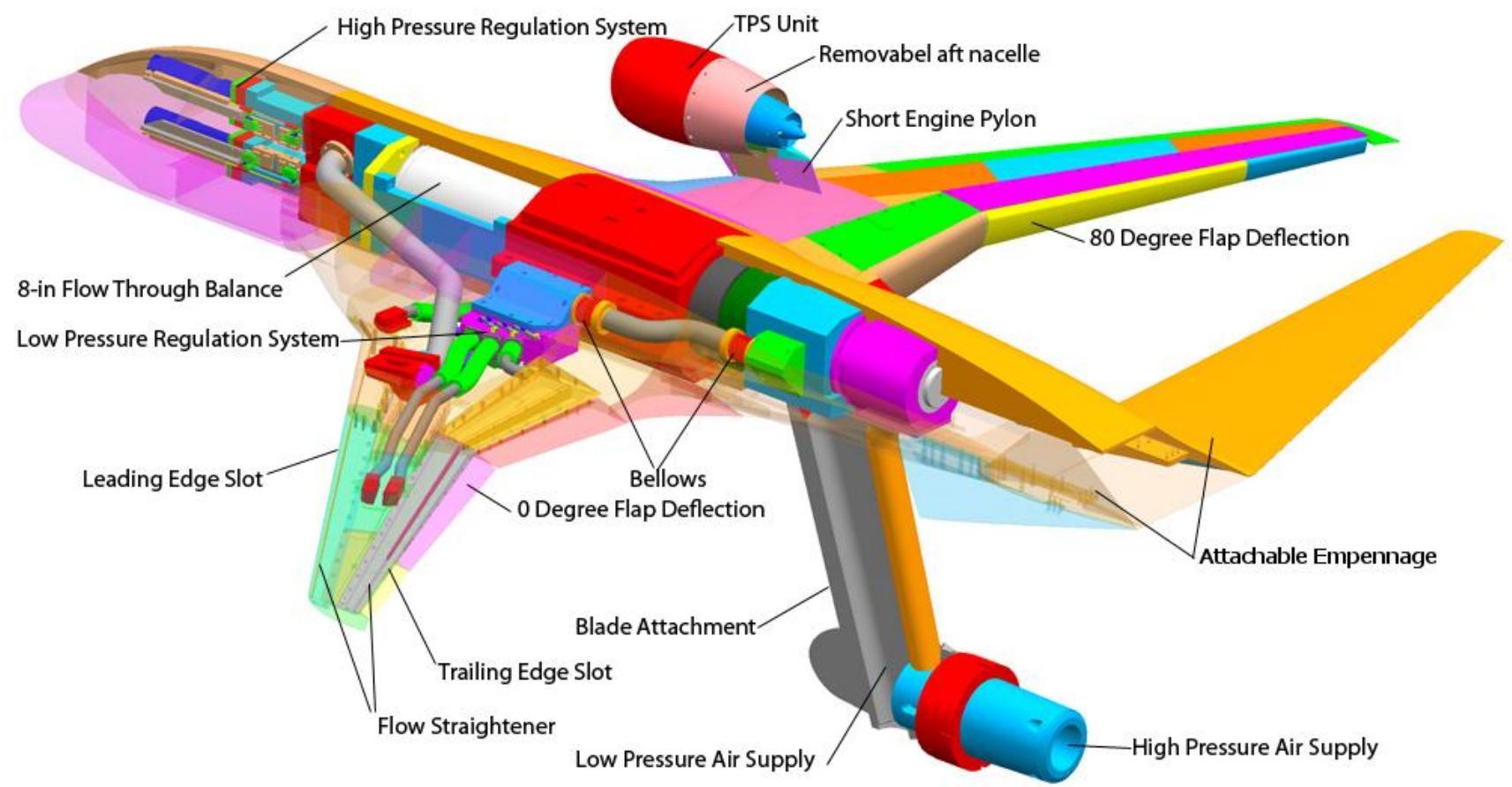

Figure 33. Overview of AMELIA's internal systems.

\section{Acknowledgments}

The calibration was conducted in an effort to fulfill requirements of the NRA contract number \#NNL07AA55C funded by Subsonic Fixed Wing Program. Success in achieving uniform slot flow couldn't have been gained without the guidance provided by Mike Rogers, Craig Hange, Bob Lockyer, Clif Horne, Bob Englar, and Greg Jones. This portion of the project could not be completed without the help of the Fluid Mechanics Lab at NASA Ames-in particular Rabi Mehta, Kurt Long, Jim Ross, Kevin James, Nate Burnside, Hiro Kumagai, Barry Porter, and Ted Garbeff. And finally, a personal Thank You to both John Wallace and Dennis Acosta who got us out of many sticky situations.

\section{References}

${ }^{1}$ Jameson, K., Marshall, D., Ehrmann, R., Paciano, E., Englar, R.J., and Horne, W. C., "Part 1: The Wind Tunnel Model Design and Fabrication of Cal Poly's AMELIA 10 Foot Span Hybrid Wing-Body Low Noise CESTOL Aircraft," Jan 2011, AIAA-2011-1306.

${ }^{2}$ Jameson, K., Marshall, D., Ehrmann, R., Paciano, E., Englar, R.J., and Horne, W. C., "Part 2: Preparation for Wind Tunnel Model Testing and Verification of Cal Poly's AMELIA 10 Foot Span Hybrid Wing-Body Low Noise CESTOL Aircraft," Jan 2011, AIAA-2011-1307.

${ }^{3}$ Lichtwardt, J. A., Paciano, E. N., Marshall D. D., Jameson K. K, "STOL Performance of Cal Poly's AMELIA", Aerospace Sciences Meeting, Jan 2013, AIAA-2013-0976.

${ }^{4}$ Marshall D. D., Jameson K. K., Fong R. K., Lichtwardt J. A., Paciano E. N., “AMELIA Technical Memorandum”, NASA Ames Research Center, Jan. 2013.

${ }^{5}$ Eppel J. C., Shovlin M. D., Jaynes D. N., Englar R. J., Nichols J. H., "Static Investigation of the CirculationControl-Wing/Upper-Surface-Blowing Concept Applied to the Quiet Short-Haul Research Aircraft", NASA Technical Memorandum 84232, July 1982. 
${ }^{6}$ Milholen W. E., Jones G. S., Cagle C. M., "NASA High-Reynolds Number Circulation Contorl Research Overview of CFD and Planned Experiments (Invited)", AIAA Aerospace Sciences Meeting, Orlando Florida, January 2010, AIAA 2010-344.

${ }^{7}$ Englar R. J., Blaylock G. M., Gaeta R. J., Jones G. S., Milholen W. E., "Recent Experimental Development of Circulation Control Airfoils and Pneumatic Power-Lift Systems"

${ }^{8}$ Novak C. J., Cornelius K. C., "Investigations of a Circulation Control Airfoil Flowfield Using an Advanced Laser

Velocimeter", NASA Conference Publication 2432, Proceedings of the Circulation Control Workshop, NASA Ames Research Center, Moffett Field CA, Feb. 1986.

${ }^{9}$ Englar R. J., "Subsonic Two-Dimensional Wind Tunnel INV of the High Lift Capability of Circulation Control Wing Sections", David W. Taylor Naval Ship R\&D Center, April 1975.

${ }^{10}$ Englar R. J., "Two Dimensional Transonic Wind Tunnel Tests of Three 15-Percent Thick Circulation Control Airfoils", Naval Ship Research and Development Center, Washington DC, December 1970.

${ }^{11}$ Wood N., Nielsen J., "Circulation Control Airfoils Past, Present, Future", AIAA $23^{\text {rd }}$ Aerospace Sciences Meeting, Reno Nevada, January 1985.

${ }^{12}$ Alley N. R., Steele J., Neidhoefer J. C., Englar R. J., Blaylock G., "Development of a Cruise-Efficient ExtremeSTOL-Capable Demonstrator UAV”, Atlanta Georgia, April 2010.

${ }^{13}$ Wetzel D., Griffin J., Liu F., Cattafesta L., "An Experimental Study of a Circulation Control Airfoil Trailing Edge Flow Field", $5^{\text {th }}$ Flow Control Conference, Chicago Illinois, June-July 2010. 